\title{
Emerging role of radiolabeled nanoparticles as an effective diagnostic technique
}

\author{
André Luís Branco de Barros ${ }^{1,2,3^{*}}$, Andrew Tsourkas ${ }^{3}$, Babak Saboury ${ }^{2}$, Valbert Nascimento Cardoso ${ }^{1}$ \\ and Abass Alavi ${ }^{2}$
}

\begin{abstract}
Nanomedicine is emerging as a promising approach for diagnostic applications. Nanoparticles are structures in the nanometer size range, which can present different shapes, compositions, charges, surface modifications, in vitro and in vivo stabilities, and in vivo performances. Nanoparticles can be made of materials of diverse chemical nature, the most common being metals, metal oxides, silicates, polymers, carbon, lipids, and biomolecules. Nanoparticles exist in various morphologies, such as spheres, cylinders, platelets, and tubes. Radiolabeled nanoparticles represent a new class of agent with great potential for clinical applications. This is partly due to their long blood circulation time and plasma stability. In addition, because of the high sensitivity of imaging with radiolabeled compounds, their use has promise of achieving accurate and early diagnosis. This review article focuses on the application of radiolabeled nanoparticles in detecting diseases such as cancer and cardiovascular diseases and also presents an overview about the formulation, stability, and biological properties of the nanoparticles used for diagnostic purposes.
\end{abstract}

Keywords: nanoparticles, PET imaging, SPECT imaging, tumor, inflammation, cardiovascular disease

\section{Review \\ Introduction}

Nanomedicine can be defined as the use of nanoparticles for diagnosis, monitoring physical and pathologic processes, for therapy, and for control of biological systems [1]. Nanoparticles are defined as structures that are nanometers in size (often smaller than $100 \mathrm{~nm}$ ) [2-4]. As small structures, they extravasate through the endothelial cell layers and interact with the cell structures of various tissues, but they are also large enough to transport high payloads of therapeutic or diagnostic agents (e. g., radioisotopes for molecular imaging) [5]. In contrast to atoms and traditional molecules, nanomaterials have an immense available surface area per unit of volume and tunable optical, electronic, magnetic, and biologic properties. They can be engineered to have different sizes, shapes, chemical compositions, surface chemical characteristics, and hollow or solid structures [6,7].

\footnotetext{
* Correspondence: brancodebarros@yahoo.com.br

${ }^{1}$ Pharmacy School, Universidade Federal de Minas Gerais, Belo Horizonte,

Minas Gerais 31270-910, Brazil

${ }^{2}$ Department of Radiology, Hospital of the University of Pennsylvania,

Philadelphia, PA 19104, USA

Full list of author information is available at the end of the article
}

Nanoparticles can be made of materials of diverse chemical nature, the most common being metals, metal oxides, silicates, polymers, carbon, lipids and biomolecules. Nanoparticles exist in several different morphologies, such as spheres, cylinders, platelets, and tubes. Generally, they are designed with surface modifications tailored to meet the needs of specific applications [8]. When used for in vivo studies, nanoparticles are typically coated with a hydrophilic polymer on their surface. The most broadly used polymer is polyethylene glycol (PEG), which reduces their uptake by the reticuloendothelial system (RES) and increases circulation time when compared with uncoated counterparts [9-11]. In addition, with this approach, aggregation between particles and association with serum and tissue proteins are diminished. Furthermore, solubility in serum increases due to the hydrophilic character of ethylene glycol units. As a result, liver uptake for those particles is significantly lower than that of non-PEGylated nanoparticles, allowing nanoparticles to remain in the blood pool for an extended period of time [12].

Thus far, the most prominent areas where the utility of nanomedicine has been explored are for treatment and imaging of cardiovascular diseases and cancer [13]. 
Two approaches are generally used to access these tissue structures. First, nanoparticles can take advantage of the increased vascular permeability and pass through the fenestrations that are present in vessels. Such spontaneous accumulation or passive targeting is known as the enhanced permeability and retention effect (EPR effect). [14-16]. Second, molecules can be attached to the surface of these nanoparticles to target specific cells or tissues (active targeting) (Figure 1) [17]. A diverse range of molecules has already been used to achieve higher drug concentration in diseased tissues, including V-CAM, I-CAM, folate, peptides, antibodies, etc. [18-21]. In addition, nanoparticles have been prepared with two different ligands. This dual ligand approach has demonstrated success in improving the selectivity when compared to a single ligand approach [22,23].

This review will focus on radiolabeled nanoparticles for diagnostic applications since we consider them to be a promising approach for early diagnosis (Figure 2). Radiotracer-based imaging either using single-photon emission computed tomography (SPECT) or positronemission tomography (PET) is particularly suited for examining targeted in vivo molecular imaging approaches. The major advantages of SPECT and PET molecular imaging techniques over other approaches are that they are highly sensitive and specific, allow accurate quantification, and there is no limit to tissue penetration in any organ. The characteristics of each modality are summarized in Table 1 [24-26]. Gamma emitters with energies in the range of 100 to $300 \mathrm{keV}$ can be used for planar imaging or SPECT imaging, and a variety of positron-emitting radionuclides appears suitable for PET studies (Table 2) [27].

\section{Liposomes}

Over the past few decades, liposomes have received widespread attention as carrier compounds for therapeutic and/or diagnostic purposes. Liposomes, first described by Bangham and co-workers, are spherical vesicles which form when phospholipids are exposed to an aqueous environment $[28,29]$. The lipid components of liposomes are predominantly phospholipids (e.g., phosphatidylcholine, phosphatidylethanolamine). However, other compounds can be added to liposomal preparation to provide more stability to the vesicles, such as cholesterol [30]. Because of the hydrophobic lipid bilayer surrounding an aqueous core volume, liposomes are suitable for encapsulating hydrophobic agents in the lipid shell, hydrophilic agents in the aqueous core, and amphiphilic agents distributed through the hydrophobic/ hydrophilic domains. Typically, liposomes can be classified according to their size, charge, and lipid composition. In regard to size, liposomes can be divided into three categories: small unilamellar vesicles or SUV (25 to $100 \mathrm{~nm}$ ), large unilamellar vesicles or LUV $(>100 \mathrm{~nm}$ ), and multilamellar vesicles or MLV (100 to $1,000 \mathrm{~nm}$ ) [31]. When superficial charge is considered, liposomes can be neutral or charged. Liposomes that are negatively or positively charged have been reported to have shorter half-lives, some toxicity, and rapid blood

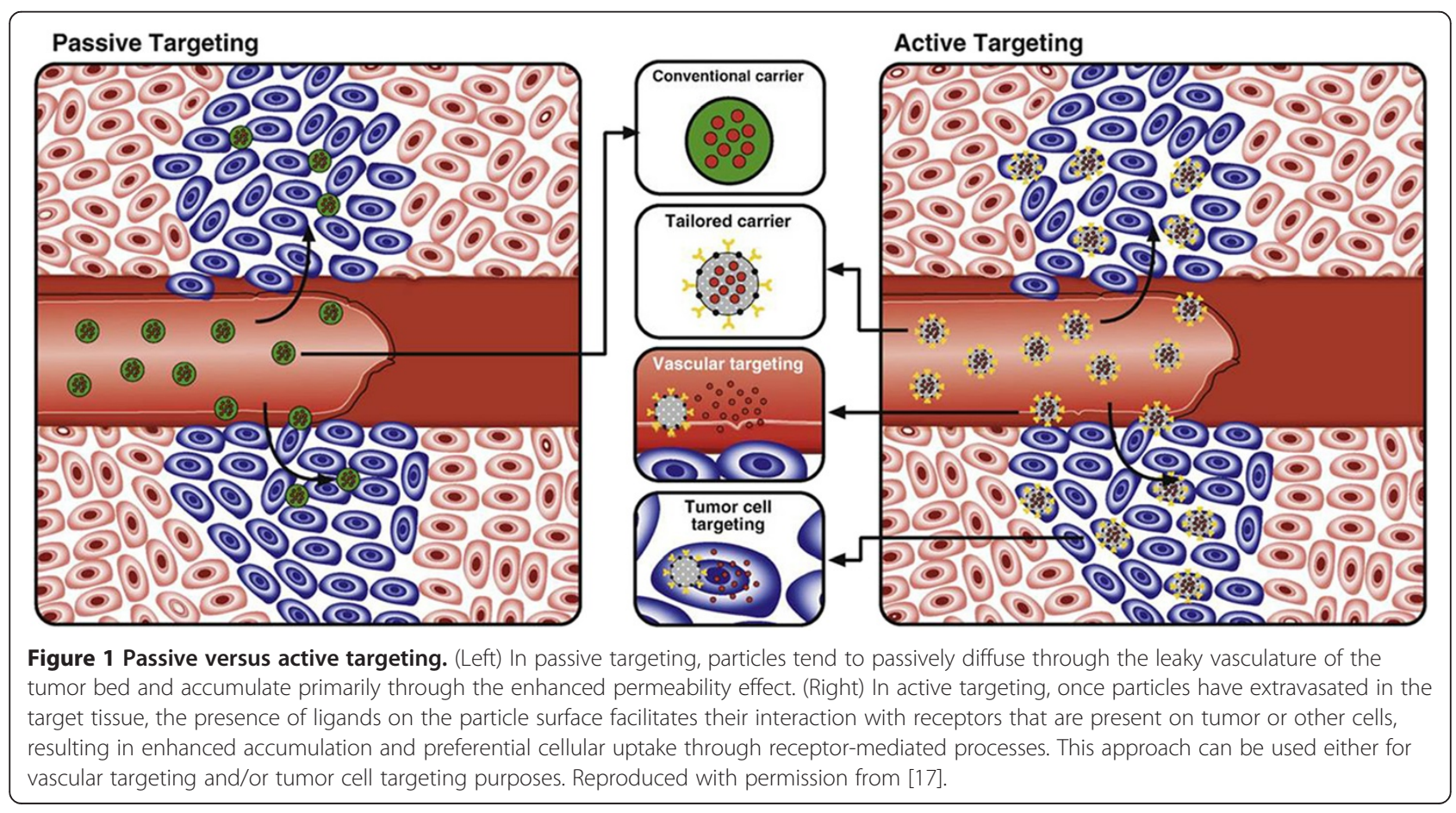




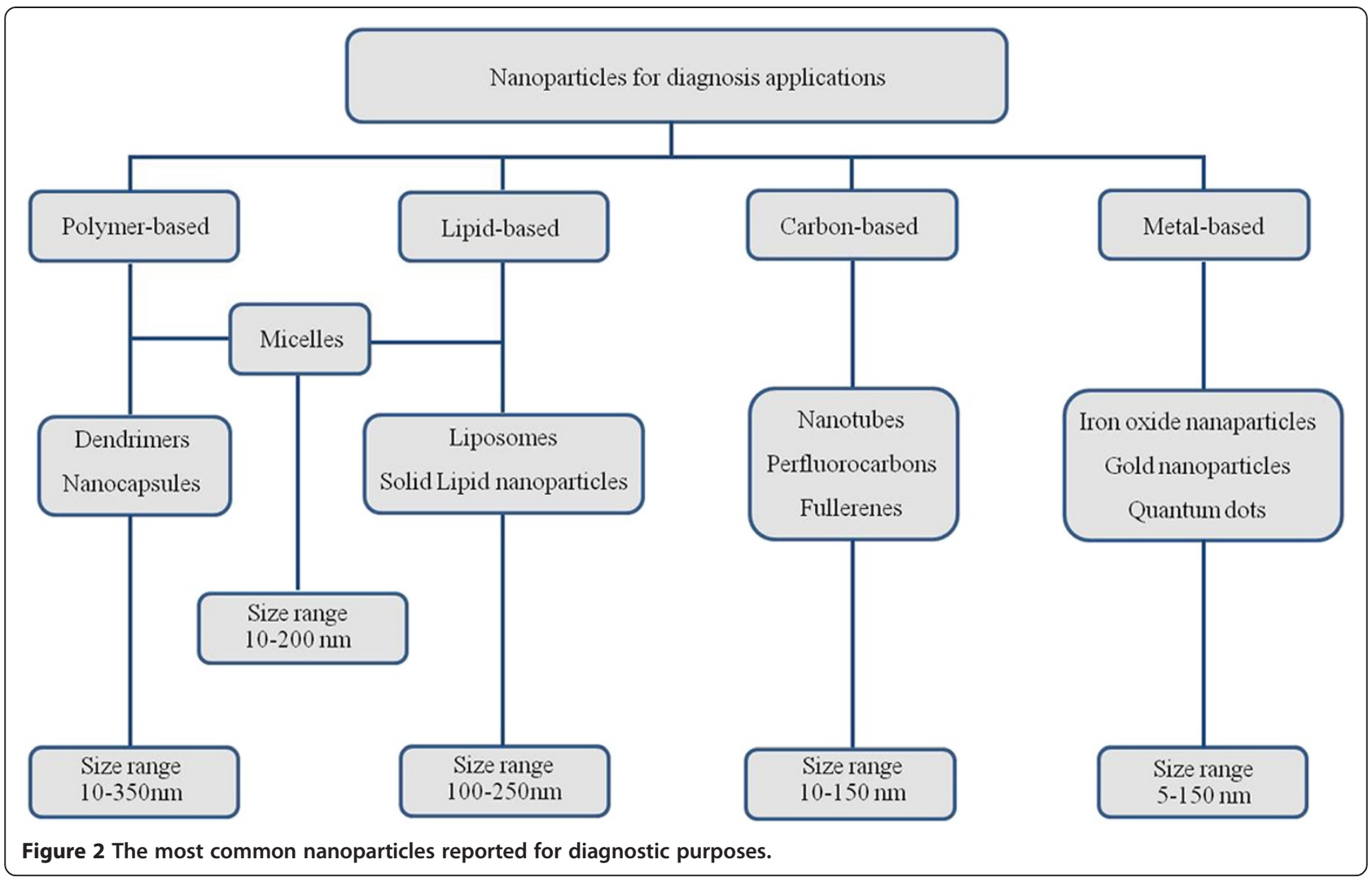

clearance [32,33]. At least three different classes of liposomal composition are described: (1) Conventional liposomes or the first generation of liposomes are composed of natural phospholipids or lipids. Addition of cholesterol to conventional liposomes has been attempted in order to improve bilayer stability. However, these kinds of liposomes have encountered several challenges, including high instability in plasma, which results in short blood circulation half-life [9,34]. (2) Stealth liposomes or long-circulanting liposomes were synthesized by conjugating hydrophilic polymers, which increase their circulation half-life [9-11]. (3) Targeted liposomes have been engineered with different types of target moieties, such as antibodies, peptides, folic acid, and carbohydrate. Indeed, targeted liposomes are able to increase the concentration of the therapeutic or diagnostic agent in specific tissues/cells that overexpress the target receptors, antigens, or unregulated selectins [35-38]. A new generation of liposomes (e.g., stimuli-sensitive) has been developed in order to improve drug delivery. One example is a $\mathrm{pH}$-sensitive liposome used to improve the endosomal release of a drug-loaded liposome into the cytoplasm $[39,40]$.

Liposomes labeled with radioisotopes have been used for PET and SPECT imaging [29,41-45]. Dams and coworkers have demonstrated the use of ${ }^{99 \mathrm{~m}} \mathrm{Tc}$-PEG liposomes for scintigraphic detection of inflammation and infection. These particles take advantage of the high permeability to extravasate to sites of inflammation and/or infection. A high correlation was observed between

Table 1 Characteristics of imaging techniques [20]

\begin{tabular}{lllll}
\hline Imaging modality & Spatial resolution & Depth of penetration & Sensitivity (mol/L) & Molecular probe \\
\hline PET & 1 to $2 \mathrm{~mm}$ & No limit & $10^{-11}$ to $10^{-12}$ & $\mathrm{ng}$ \\
SPECT & 0.3 to $1 \mathrm{~mm}$ & No limit & $10^{-10}$ to $10^{-11}$ & $\mathrm{ng}$ \\
FMT (optical) & 1 to $3 \mathrm{~mm}$ & $<5 \mathrm{~cm}$ & $10^{-6}$ to $10^{-12}$ & $\mathrm{\mu g}$ \\
MRI & 50 to $250 \mu \mathrm{m}$ & No limit & $10^{-3}$ to $10^{-5}$ & $\mathrm{\mu g}$ to $\mathrm{mg}$ \\
X-Ray, CT & 25 to $150 \mu \mathrm{m}$ & No limit & - & $\mathrm{mg}$ \\
Ultrasound & 30 to $500 \mu \mathrm{m}$ & mm to cm & $10^{-6}$ to $10^{-9}$ & $\mathrm{mg}$ to $\mathrm{mg}$ \\
\hline
\end{tabular}

PET, positron emission tomography; SPECT, single-photon emission computed tomography; FMT, fluorescence molecular tomography; MRI, magnetic resonance imaging; $\mathrm{CT}$, computed tomography. 
Table 2 Most common radionuclides for scintigraphic imaging [23]

\begin{tabular}{llll}
\hline Radionuclides & Emission type & Half-life & $\boldsymbol{E}_{\max }(\boldsymbol{\gamma})[\mathrm{keV}]$ \\
\hline${ }^{131} \mathrm{I}$ & $\mathrm{Y}(81.2 \%), \beta$ & $8.0 \mathrm{days}$ & $284,364,637$ \\
${ }^{67} \mathrm{Ga}$ & $\mathrm{Y}$ & $78.3 \mathrm{~h}$ & $93,184,300,393$ \\
${ }^{111} \mathrm{In}$ & Auger, $\mathrm{Y}$ & $67.2 \mathrm{~h}$ & 171,245 \\
${ }^{123} \mathrm{I}$ & Auger, $\mathrm{Y}$ & $13.2 \mathrm{~h}$ & 159 \\
${ }^{99} \mathrm{~m}_{\mathrm{TC}}$ & $\mathrm{Y}$ & $6.0 \mathrm{~h}$ & 140 \\
${ }^{18} \mathrm{~F}$ & Positron & $1.83 \mathrm{~h}$ & 511 \\
${ }^{64} \mathrm{Cu}$ & Positron & $12.7 \mathrm{~h}$ & 511 \\
${ }^{188} \mathrm{Re}$ & $Y(15 \%), \beta$ & $16.9 \mathrm{~h}$ & 155 \\
\hline
\end{tabular}

scintigraphic results and biopsy, culture, surgery, and follow-up to 6 months. It was found that infection and inflammatory sites could be imaged with radiolabeled liposomes [46]. Recently, Li et al. have reported the use of indium $\left({ }^{111} \mathrm{In}\right)$-loaded liposomes, surface-targeted with antibodies to the low-density lipoprotein receptor LOX-1. These liposomes were successfully used to acquire molecular images of atherosclerotic plaques in ApoE -/- mice. Mice injected with control liposomes, coated with nonspecific IgG (nIgG), did not exhibit any detectable signal in the atherosclerotic plaques (Figure 3) [47]. Examples reported in this article, containing animal or human studies, had been approved by an appropriate ethics committee.

Studies conducted by Harrington et al. have demonstrated the potential application of liposomes in tumor diagnosis. Seventeen patients with different types of cancer were evaluated by scintigraphic imaging after injection of ${ }^{111}$ In-DTPA-labeled PEGylated liposomes. Positive images were obtained in 15 studies. This data suggested that liposomes can be an interesting vehicle for delivering diagnostic agents to tumors [48]. Another study reported the biodistribution of ${ }^{188} \mathrm{Re}-\mathrm{N}, \mathrm{N}$-bis(2mercaptoethyl)- $N^{\prime}, N^{\prime}$-diethylethylenediamine

(BMEDA)-labeled PEGylated liposomes in murine C26colon tumor-bearing mice. MicroSPECT/computed tomography (CT) images were acquired from 1 to $72 \mathrm{~h}$. Image analysis revealed that liposomes had a higher tumor uptake at all time points when compared with unencapsulated ${ }^{188}$ Re-BMEDA (Figure 4). Biodistribution data were used to confirm higher uptake at $24 \mathrm{~h}$ post-injection ( $3.62 \pm 0.73 \%$ injected dose (ID)/g) when compared with unencapsulated radiopharmaceutical $(0.51 \pm 0.06 \% \mathrm{ID} / \mathrm{g})[49]$.

Typically, positron emitters have short half-lives (Table 2). As a result, in selecting the appropriate candidates, preparation schemes that are fast and least complicated should be considered as liposome tracers. In this context, Petersen et al. have reported recently a successful method to rapidly encapsulate radionuclides (remote loading method), showing a feasible way to obtain ${ }^{64} \mathrm{Cu}$-loaded PEGylated liposomes with high loading efficiency. Biodistribuition studies showed high tumor uptake at 24 hours post-liposome injection $(5.0 \% \mathrm{ID} / \mathrm{g})$. MicroPET/CT images visualized an implanted colon adenocarcinoma in a mouse model at $24 \mathrm{~h}$ postliposome injection (Figure 5) [50].

\section{Iron oxide nanoparticles}

Over the past two decades, iron oxide nanoparticles have received enormous attention for imaging applications. These nanoparticles can be divided into two categories based on their structural configuration: (1) a magnetic particle core (typically magnetite, $\mathrm{Fe}_{3} \mathrm{O}_{4}$, or maghemite,

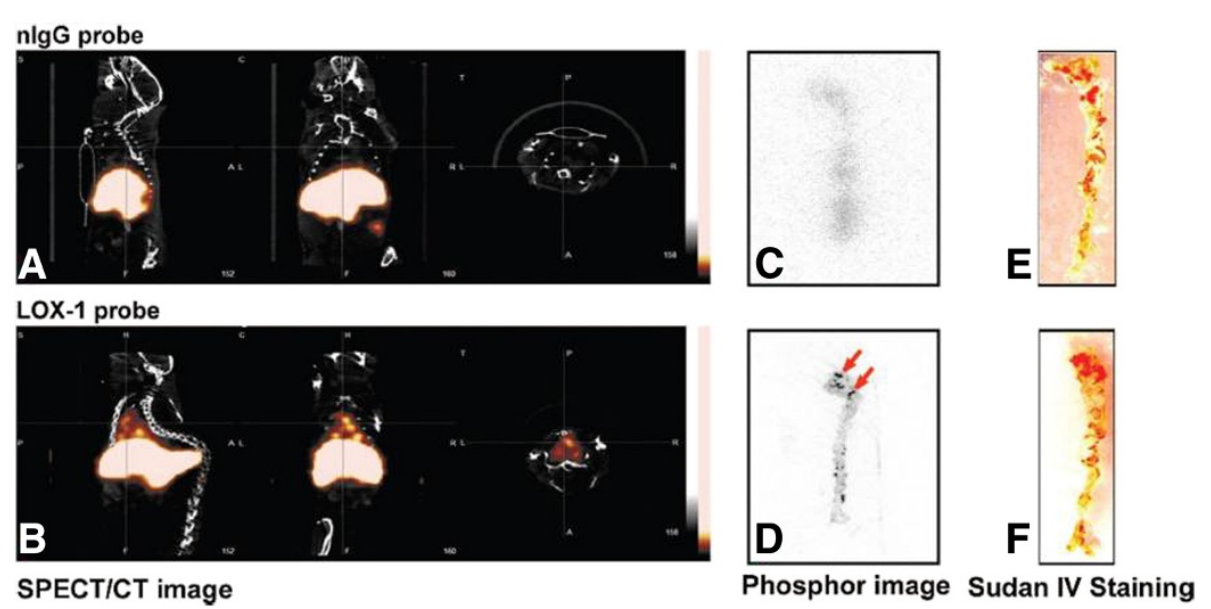

Figure 3 Images of mice injected with ${ }^{111}$ In-loaded liposomes. (A) SPECT and (C) ex vivo phosphor imaging showed no focal, aortic arch hot spots in ApoE -/- mice injected with the nlgG probe, whereas all ApoE -/- mice injected with the LOX-1 probe revealed hot spots in the aortic arch ((B) includes sagittal, coronal, and transverse planes), confirmed by (D) ex vivo phosphor imaging. Sudan IV staining demonstrated comparable plaque distribution pattern for the (E and $\mathbf{F})$ two groups. Reproduced with permission from [47]. 


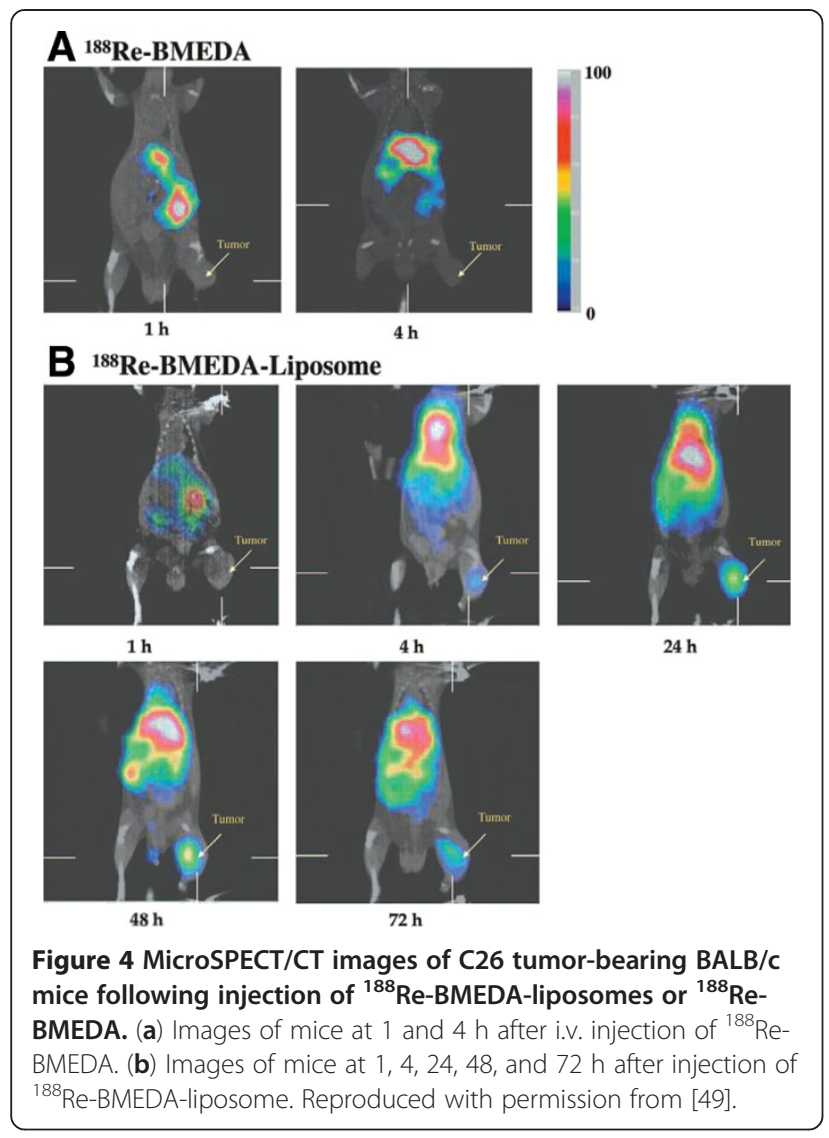

$\mathrm{Fe}_{2} \mathrm{O}_{3}$ ) coated with a hydrophilic and biocompatible polymer, such as PEG, dextran, alginate, and poly(D,Llactide-co-glycolide); and (2) a porous biocompatible polymer in which iron oxide nanoparticles are entrapped within the polymer matrix [51]. The coating process is important to provide colloidal stability, biocompatibility, and reduced uptake by the RES. The presence of a coating material is essential to avoid the premature clearance from the blood [52]. Generally, coated and neutral surfaces are preferred to minimize opsonization and clearance [53]. In addition to the coating material, nanoparticle size also plays a critical role in dictating blood circulation times since, in general, nanoparticles larger than $200 \mathrm{~nm}$ are rapidly removed from bloodstream via the RES system, and nanoparticles smaller than $10 \mathrm{~nm}$ undergo renal filtration. Therefore, nanoparticles with mean diameters between 10 and $100 \mathrm{~nm}$ are generally preferred since they can attain much longer circulation times and, consequently, can achieve higher accumulation at the target site $[54,55]$.

In regard to their hydrodynamic diameter, iron oxide nanoparticles can be classified into superparamagnetic iron oxide (SPIO) (60 to $250 \mathrm{~nm}$ ), ultra small paramagnetic iron oxide (USPIO) (5 to $40 \mathrm{~nm}$ ), and micrometersized particles of iron oxide (MPIO) (0.9 to $8 \mu \mathrm{m}$ ). USPIO can be further chemically modified, termed cross-linked iron oxide nanoparticles (CLIO), in order to attach new molecules for targeting purposes [56-58]. Several studies have been reported using CLIO for the active targeting of various diseases, including cancer and atherosclerosis [59-64].

Because of their magnetic properties, iron nanoparticles have been studied extensively as magnetic resonance imaging (MRI) contrast agents. Nevertheless, some studies have reported their use for both MRI and SPECT or PET [65-69]. This approach poses numerous benefits since it takes advantage of high PET sensitivity and the high spatial resolution of MRI. As a result, it should theoretically be possible to obtain 'perfect' spatial registration of molecular/functional PET and anatomic/ functional MRI [70-72].

Lee et al. have reported a radiolabeled iron oxide nanoparticle conjugated with cyclic arginine-glycineaspartic (RGD). These particles were functionalized with DOTA for labeling with ${ }^{64} \mathrm{Cu}$. The iron nanoparticles, which had a hydrodynamic diameter of $45 \mathrm{~nm}$, showed high avidity for the integrin $\alpha_{v} \beta_{3}$ in a competitive binding assay. In addition, PET and MR images were acquired showing delivery of RGD-iron nanoparticles to U87MG human glioblastomas in tumor-bearing mice. The highest uptake at the tumor site was achieved at $4 \mathrm{~h}$ post-injection $(10.1 \% \mathrm{ID} / \mathrm{g})$. When RGD receptors were blocked with unconjugated RGD, the tumor uptake was significantly reduced, confirming specificity for integrin $\alpha_{v} \beta_{3}$ [18]. Recently, Xie et al. have performed PET/nearinfrared fluorescence (NIRF)/MRI tri-functional iron oxide nanoparticles for tumor detection. The particles were labeled with ${ }^{64} \mathrm{Cu}$-DOTA and Cy5.5 and tested in a subcutaneous U87MG xenographic mouse model. For PET/NIRF/MRI images, clear tumor delineation was

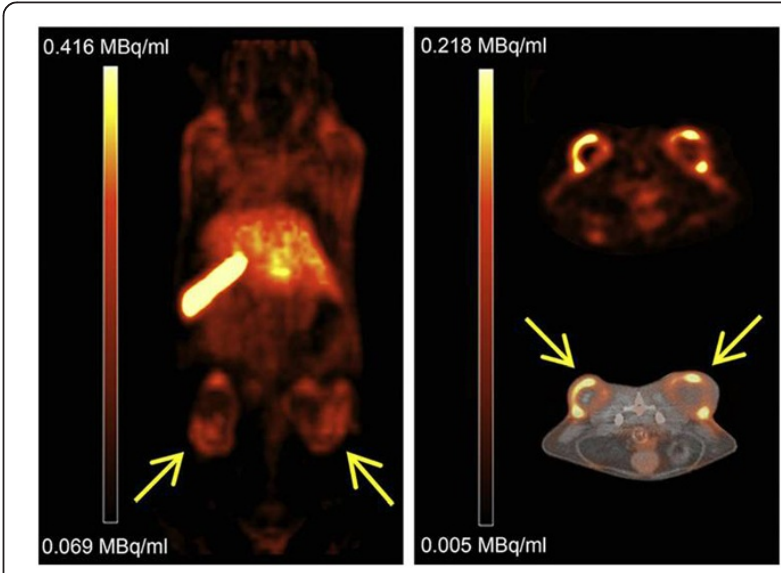

Figure 5 PET/CT images of ${ }^{64} \mathrm{Cu}$ liposome distribution in HT29 tumor-bearing mice. Tumors were implanted on the right and left flanks. Coronal PET image $24 \mathrm{~h}$ after injection (left). Axial PET image (right top) and axial PET/CT fusion (right bottom) images $24 \mathrm{~h}$ after injection. Adapted with permission from [50]. 
observed by all three imaging modalities (Figure 6). Compared with NIRF results, the PET imaging showed much higher tumor-to-muscle ratios, reaching $8.28 \%$ ID/ $\mathrm{g}$ at $18 \mathrm{~h}$ [73].

A dextran-coated and DTPA-modified magnetofluorescent 20-nm nanoparticle was prepared and radiolabeled with ${ }^{64} \mathrm{Cu}$ to yield a PET, magnetic resonance, and optically detectable imaging tracer for macrophages in inflammatory atherosclerosis in ApoE -/- mice. Biodistribution studies revealed that the percent injected doses accumulated in aortas and carotid arteries were $260 \%$ and 392\% higher, respectively, than in wild-type mice. $\mathrm{PET} / \mathrm{CT}$ images showed robust signal in the aortic root and arch (mouse atheroma), showing a target-tobackground ratio equal to 5.1 [74]. Another study recently published by Nahrendorf and co-workers used ${ }^{18} \mathrm{~F}$-CLIO for detection of macrophages in aortic aneurysms induced in ApoE -/- mice. The nanoparticles were also labeled with a near-infrared fluorochrome. PET/CT images showed significantly higher uptake in the aneurismal aortic section compared with what was found in the wild-type aorta. In addition, the PET signal within the aneurysm was stronger than in atherosclerotic plaques. Ex-vivo imaging by autoradiography and fluorescence reflective microscope confirmed high uptake of ${ }^{18} \mathrm{~F}$-CLIO in the aneurysm (Figure 7) [75].

\section{Gold nanoparticles}

Gold nanoparticles have received special attention in the biomedical field due to their biocompatibility, facile conjugation to biomolecules, and the unique optical properties conferred by their localized surface plasmon resonance [76]. Moreover, gold is resistant to oxidation under physiological or ambient conditions, which permit unrestricted interaction of gold with the biological environment [23]. The optical properties of gold depend on the nanoparticle size and shape. One can manipulate the shape of gold nanostructures to control their electronic
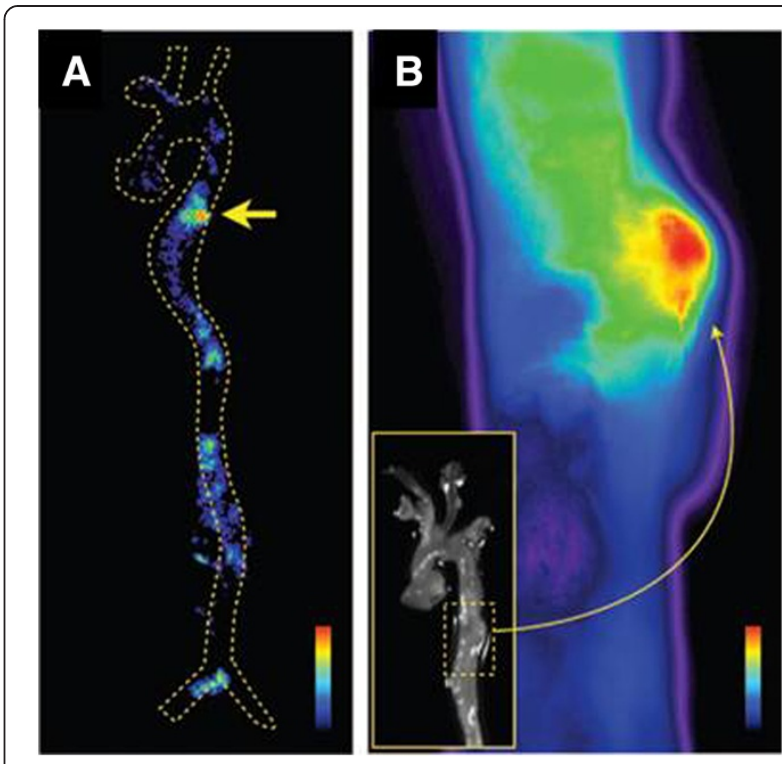

Figure 7 Autoradiography and fluorescence reflectance image of the aorta. (A) Autoradiography at an aneurysm in the descending thoracic aorta (arrow). (B) Fluorescence reflectance image of the same aorta. Nuclear and optical imaging concordantly showed nanoparticle accumulation in the aneurysmatic vessel wall. Adapted with permission from [75].

and associated optical properties for the desired applications.

Gold nanoparticles can be manufactured into different shapes, such as gold nanospheres, nanorods, nanocages, and nanostars [77]. Their widespread utilization in biological assays relies on the availability of synthetic methods yielding nanoparticles with desired characteristics including high solubility in water, adequate morphology, size dispersion, and surface functionalities. The most common method to prepare gold nanoparticles is the citrate reduction method of Turkevich [78]. This approach is very convenient since appropriate functionality can be easily applied by replacement of the citrate. The
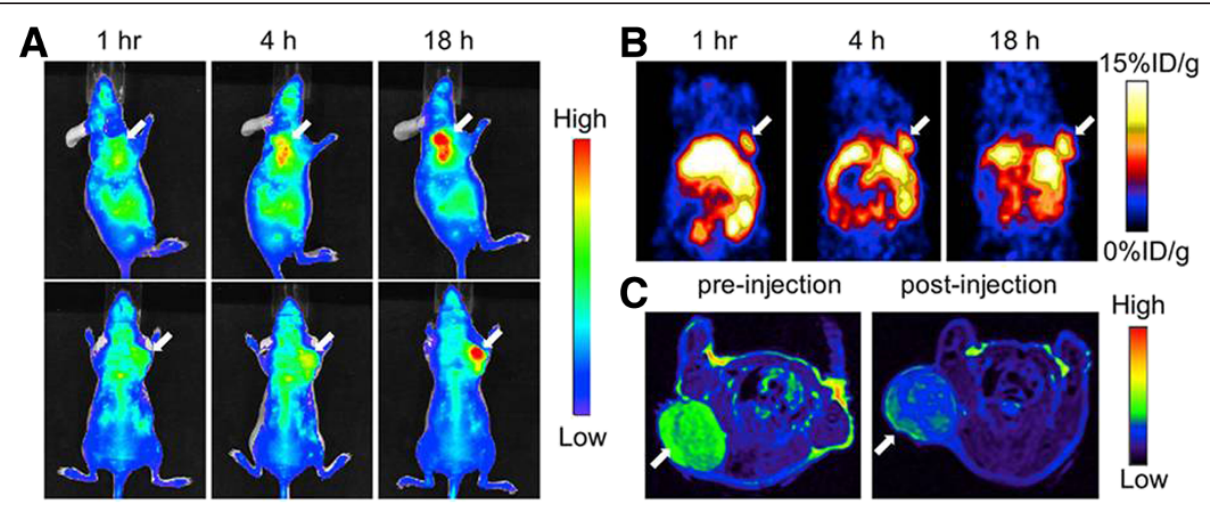

Figure 6 In vivo NIRF (a) and PET (b) images of mouse injected with iron oxide nanoparticles. Images were acquired 1, 4, and 18 h after injection. (c) MRI images acquired before and $18 \mathrm{~h}$ after injection. Reproduced with permission from [73]. 
nanoparticle surface can be modified in order to achieve specific labeling with biomolecules, such as antibodies, cardohydrates, and proteins.

In the imaging field, gold nanoparticles have shown promise for their use in computed tomography, Raman spectroscopy, and photoacoustic imaging. Recently, several reports have also indicated the use of gold nanoparticles labeled with gamma emitters or positron emitters for multimodality imaging, such as PET/CT imaging [79-82]. This approach takes advantage of higher PET sensitivity and an accurate localization provided by CT. In this context, Xie et al. have prepared a radiolabeled gold nanoshell for tumor diagnosis. Gold nanoparticles were coated with PEG2k-DOTA for ${ }^{64} \mathrm{Cu}$ chelation. After surface modification, the nanoparticles' diameter was $170 \mathrm{~nm}$, and the surface charge was $-5 \mathrm{mV}$. The radiolabeling efficiency was $81.3 \%$, and ${ }^{64} \mathrm{Cu}$ binding was shown to be stable for $3 \mathrm{~h}$. PET imagines were acquired at different times, using ${ }^{64} \mathrm{Cu}$-DOTA and ${ }^{64} \mathrm{Cu}$-DOTAPEG2k as controls. The ${ }^{64} \mathrm{Cu}$-nanoparticles showed higher accumulation in the tumor site, mainly at 20 and $44 \mathrm{~h}$ post-injection (Figure 8) [83].

Morales-Ávila and co-workers have recently reported the use of ${ }^{99 \mathrm{~m}}$ Tc-labeled gold nanoparticles conjugated with $\mathrm{c}[\mathrm{RGDfk}(\mathrm{C})]$ for tumor imaging. In vivo studies were performed in C6 human glioma-bearing athymic mice. Nanoparticles showed rapid blood clearance, with less than $0.5 \% \mathrm{ID} / \mathrm{g}$ remaining in the blood compartment

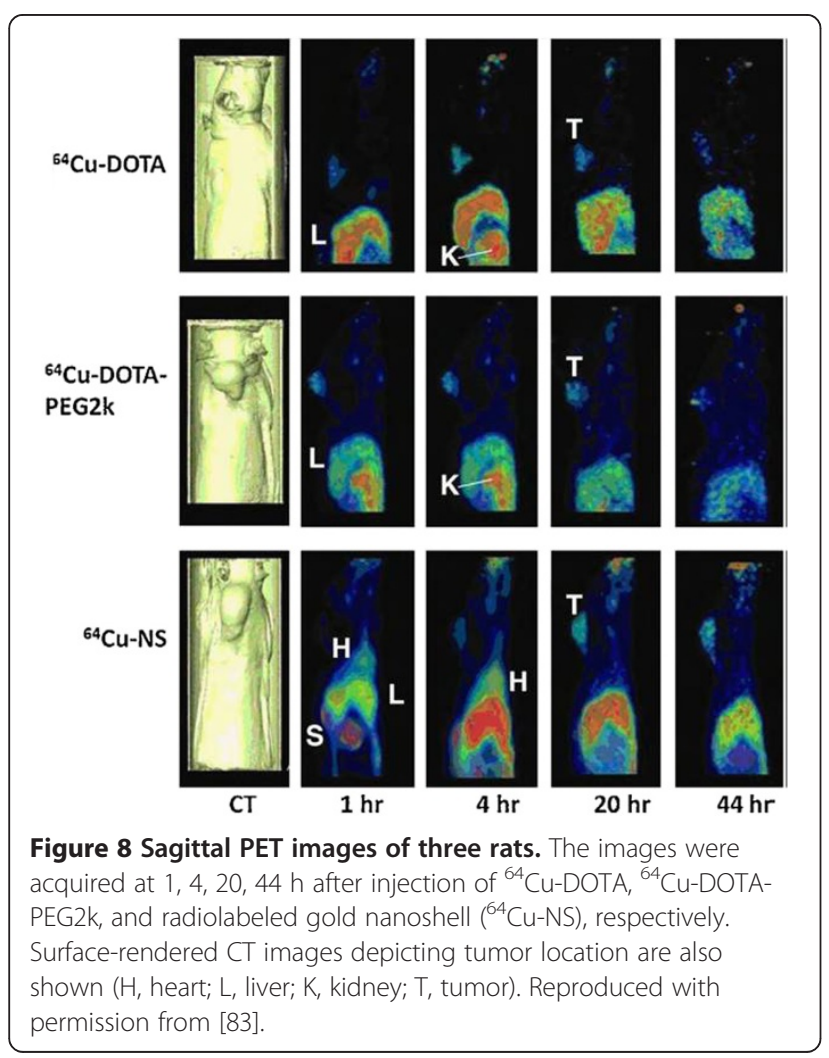

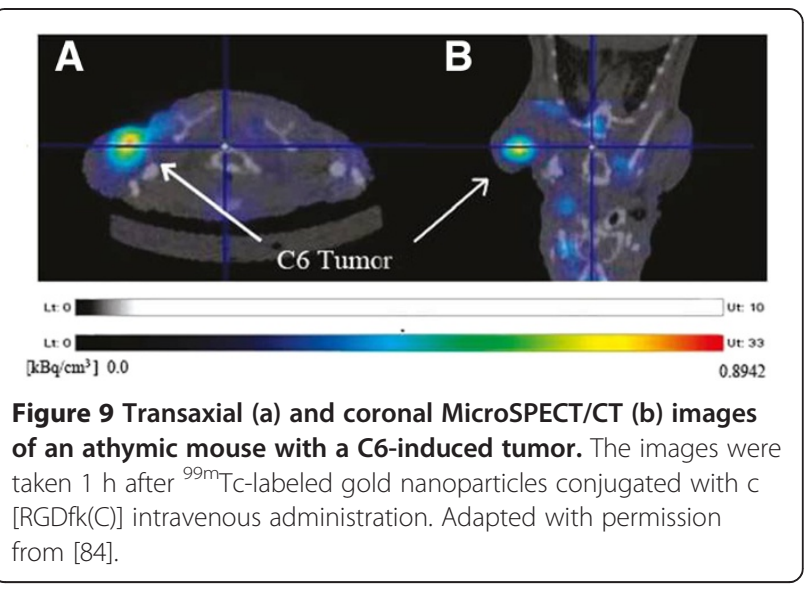

$1 \mathrm{~h}$ post-injection. However, evident tumor uptake was observed at the same time ( $1 \mathrm{~h}$ post-injection) $(3.65 \%$ ID/g) (Figure 9) [84].

Shao et al. have reported ${ }^{125}$ I-labeled gold nanorods for imaging inflammation in an adjuvant-induced arthritic rat model. These nanoparticles were PEGylated in order to achieve long circulation and also conjugated with anti-intercellular adhesion molecule 1 antibody, which is overexpressed in arthritic diseases. Results showed higher accumulation in the inflamed joints when compared with the control group [85]. These findings further support the use of gold nanoparticles in detecting inflammation due to the increased permeability of inflamed areas, allowing for higher uptake of the diagnostic agent.

\section{Micelles}

Micelles are self-assembled nanostructures with a hydrophobic core and hydrophilic shell which are spontaneously formed above a certain concentration (critical micellar concentration). They can be constituted from lipid-based or polymer-based amphiphilic molecules [13]. Micellar formulations, including polymer micelles, have been extensively studied as molecular delivery systems [86]. In general, the hydrophobic portion of the polymer forms a semisolid core, while the hydrophilic portion of polymer forms the corona. The hydrophobic core promotes stability, while the hydrophilic shell increases solubility, prevents opsonization, and reduces RES uptake. Molecules can be physically trapped into the hydrophobic core or can be covalently bound with components of the corona [87].

The in vivo performance of micelles is controlled by several factors, such as size distribution, shape, density, deformability, and surface properties which can determine physicochemical and pathophysiological interactions. Blood stability can be affected by several factors including phagocytotic/endocytotic recognition, immune responsiveness, and vascular escape routes. In addition, 
if these nanoparticles are charged, they will be rapidly cleared from circulation. In contrast, neutral particles display longer circulation times. In general, micelles in the range of 10 to $200 \mathrm{~nm}$ are preferred since they can avoid the RES more effectively, increasing circulation half-life [88-90]. In summary, the characteristics of micelles that are favorable for in vivo imaging include facile encapsulation of a diagnostic agent, thermodynamic stability (often a low critical micellar concentration is required), and long blood circulation times, avoiding RES recognition.

In this sense, some radiolabeled micelles have been prepared for diagnostic purposes [91-94]. Zhang et al. have prepared peptide-conjugated polymeric micellar nanoparticles which were used to identify EphB4 receptors in prostate cancer in a mouse model by SPECT [93]. The same group has recently reported the use of annexin A5-conjugated polymeric micelles (CPM) for the detection of apoptosis. Annexin A5 is a protein which binds strongly and specifically to phosphatidylserine residues. These residues are present on the cell surface in the early stage of apoptosis. Micelles were labeled with ${ }^{111} \mathrm{In}$ and a near-infrared fluorescent indocyanine (Cy7)-like dye in order to acquire SPECT and optical images. Tumor apoptosis was clearly visualized in mice bearing EL4 lymphomas treated with cyclophosphamide and etoposide. On the other hand, untreated animals showed lower accumulation of the nanoparticles (Figure 10) [95]. In another study, Xiao et al. have reported a multifunctional micelle made up with a hyperbranched amphiphilic block copolymer. These particles were conjugated with cRGD peptide (for integrin $\alpha_{\mathrm{v}} \beta_{3}$ target), NOTA (a macrocyclic chelator for ${ }^{64} \mathrm{Cu}$-labeling and PET imaging), and doxorubicin (DOX) for cancer therapy. When injected into U87MG tumorbearing mice, these particles $\left({ }^{64} \mathrm{Cu}\right.$-micelle-DOX-cRGD) showed higher tumor accumulation than the nontargeted particle $\left({ }^{64} \mathrm{Cu}\right.$-micelle-DOX) used as control. Furthermore, injecting a blocking dose of cRGD peptide along with ${ }^{64} \mathrm{Cu}$-micelle-DOX-cRGD reduced tumor uptake significantly, indicating integrin $\alpha_{v} \beta_{3}$ specificity. These findings suggested that such multifunctional micelle approach can be considered a promising cancer theranostic platform [96].

\section{Carbon-based nanoparticles}

The most prominent types of carbon-based nanoparticles that have been evaluated for medical applications are carbon nanotubes, fullerenes, perfluorocarbon nanoemulsions, and graphene oxide nanoparticles. Carbon nanotubes (CNTs), first described by Iijima [97], are well-ordered hollow nanomaterials with lengths from several hundred nanometers to several micrometers and diameters of 0.4 to $2 \mathrm{~nm}$ for single-walled carbon nanotubes (SWNTs) and 2 to $100 \mathrm{~nm}$ for multi-walled carbon nanotubes (MWNTs). In recent years, efforts have been devoted to explore the potential biological applications of CNTs, which were mainly motivated by their interesting size, shape, and structure $[98,99]$. Some studies have reported the use of radiolabeled CNTs [100-104]. McDevitt et al. have prepared antibody-functionalized SWNTs labeled with indium-111 for tumor targeting. In vitro and in vivo studies were performed, and results suggested that CNTs could be used as a novel delivery platform [105]. More recently, Liu and collaborators have published in vivo biodistribution data for PEG-coated ${ }^{64} \mathrm{Cu}$-labeled SWNTs that were functionalized with RGD peptide in U87MG tumor-bearing mice. SWNTPEG5400-RGD showed higher tumor uptake (approximately $15 \% \mathrm{ID} / \mathrm{g}$ at $24 \mathrm{~h}$ post-injection) when compared with PEG-coated SWNT free of RGD (approximately 4\% $\mathrm{ID} / \mathrm{g}$ at $24 \mathrm{~h}$ post-injection) [106]. Ruggiero et al. have reported a radiolabeled carbon nanotube that targets the tumor neovasculature via the E4G10 antibody. The E4G10 antibody specifically targets the monomeric vascular endothelial-cadherin epitope expressed on tumor angiogenic vessels. PET ROI data revealed a tumor-tomuscle ratio at $96 \mathrm{~h}$ post-nanotube injection equal to

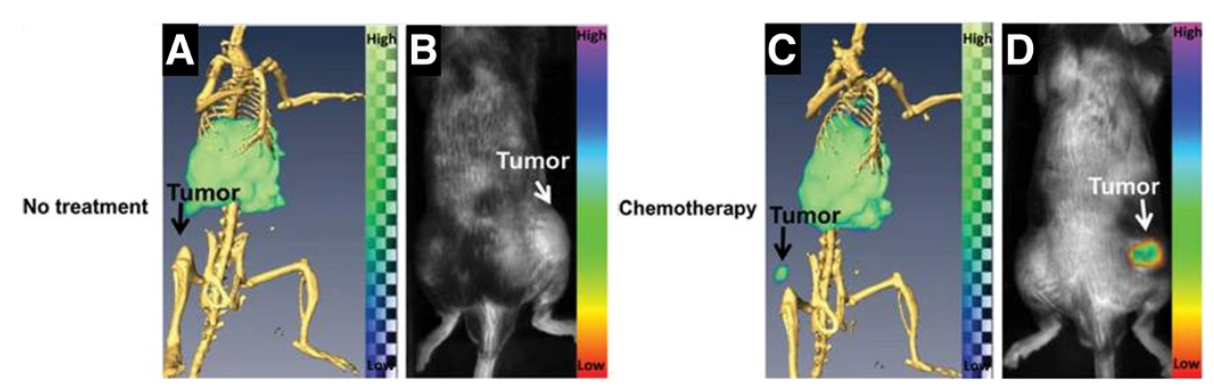

Figure 10 Imaging after administration of ${ }^{111}$ In-labeled annexin A5-CPM in untreated and treated mice. (A) Dual SPECT/CT and (B) nearinfrared fluorescence optical imaging after administration of ${ }^{111}$ In-labeled annexin A5-CPM into EL4 lymphoma-bearing mice (untreated animals). (C) Dual SPECT/CT and (D) near-infrared fluorescence optical imaging of EL4 lymphoma apoptosis after injection of ${ }^{111}$ In-labeled annexin A5-CPM into treated mice. Adapted with permission from [95]. 
5.08. This result can support the idea that CNTs can be used for medical applications, including diagnostic approaches [107].

Fullerenes were discovered in 1985 and were first studied for diagnostic purposes soon afterwards. The most representative fullerene is $\mathrm{C}_{60}$, which has a diameter around $0.7 \mathrm{~nm}$. Fullerenes naturally have poor water solubility, resulting in the formation of aggregates when administrated in biological systems. Fortunately, this inconvenience can be solved by preparing functionalized fullerenes (e.g., - $\mathrm{OH},-\mathrm{NH} 2,-\mathrm{COOH}$ ), which show adequate solubility in polar solvents $[108,109]$. Fullerenes can be used to entrap metals inside their cavity, leading to nanostructures called endohedral metallofullerenes [110]. One of the most important applications of this approach is in molecular imaging with radiotracers due to the fact that it is possible to encapsulate radioactive metals for diagnostic purposes [111-113]. Nickolic et al. have described the preparation and biodistribution of ${ }^{125}$ I-radiolabeled fullerenes. The results confirmed the possibility of using these molecules as radiotracers for in vivo studies [114].

Perfluorocarbon nanoemulsions are a multifunctional technology that are typically about $250 \mathrm{~nm}$ in diameter and have a perfluorocarbon core wrapped by a monolayer of phospholipid. Different perfluorocarbons can be used for the core, including perfluorodichlorooctane, perfluorodecaline, perfluoro 15-crown-5 ether (CE), and, most commonly, perfluorooctyl bromide (PFOB). The biocompatibility of PFOB is well documented showing no toxicity, even at large doses. The large surface area of nanoparticles can easily accommodate 100 to 500 radionuclides, allowing their application for diagnostic purposes [115,116]. $\mathrm{Hu}$ et al. have developed a $\alpha_{\mathrm{v}} \beta_{3^{-}}$ integrin-targeted ${ }^{111}$ In-perfluorocarbon nanoparticle for detecting tumor angiogenesis in rabbits. The tumor uptake in rabbits receiving $\alpha_{v} \beta_{3}$-integrin-targeted nanoparticles was four-fold higher than that in the nontarget control at $18 \mathrm{~h} \mathrm{[117].}$

Graphene oxide is a class of dual-dimensional carbonbased nanoparticles which has attracted attention due to its unique electronic, thermal, mechanical, and optical properties [118]. Several studies have reported a variety of graphene-based platforms useful for biomedical applications, including bioimaging [119-123]. The toxicity of graphene is closely related to its surface characteristics. As a result, PEG functionalized graphene oxide nanoparticles have showed minimal toxicity when administrated in mice [124]. Zhang and co-workers have reported graphene oxide nanoparticles which exhibited long blood circulation and low uptake by MPS, indicating that those particles might be used for biomedical applications [125]. Hong et al. have prepared ${ }^{66} \mathrm{Ga}$-labeled nanographene for tumor vasculature imaging. These particles were conjugated with an antibody that binds to CD105 (a marker for tumor angiogenesis) and then injected into 4T1 tumor-bearing mice. PET-CT images revealed tumor uptake, indicating nanographene affinity to tumor vasculature (Figure 11) [126].

\section{Other nanoparticles}

Besides the various nanoparticles presented in the previous sections, in order to look into new possibilities in nanotechnology-based diagnosis, other nanoparticles have been reported including quantum dots, dendrimers, nanocapsules, solid lipid nanoparticles, and silica nanoparticles.

Quantum dots are semiconductor nanocrystals made from a variety of different compounds, such as cadmium and selenide with unique optical and electrical properties [1,13,127]. Most quantum dots are composed of heavy metals that are not normally exocytosed from cells, and this can give rise to in vivo cytotoxicity and limited clinical safety. Nevertheless, interest in these structures has resurged with the advent of heavy metalfree quantum dots, which are expected to have less toxicity than earlier designs [128]. A few radiolabeled quantum dots have been reported with a variety of isotopes, such as ${ }^{125 \mathrm{~m}} \mathrm{Te},{ }^{18} \mathrm{~F}$, and ${ }^{64} \mathrm{Cu}$ [129-132]. Cai et al. have reported an amine-fuctionalized quantum dot modified with RGD peptides and DOTA chelator for PET/NIRF imaging of the integrin $\alpha_{\mathrm{v}} \beta_{3}$. Results showed high linear correlation between nuclear and optical signals. In this study, tumor uptake was $4 \% \mathrm{ID} / \mathrm{g}$ at $18 \mathrm{~h}$ post-injection [133]. Similarly, Chen et al. have prepared quantum dots conjugated with vascular endothelial growth factor (VEGF) for imaging angiogenic vessels within tumors. Both NIR fluorescence imaging and PET imaging showed specific delivery of nanoparticles to sites of VEGF receptor over expression [134].

Dendrimers are a class of well-defined nanostructured macromolecules that possess a treelike architecture

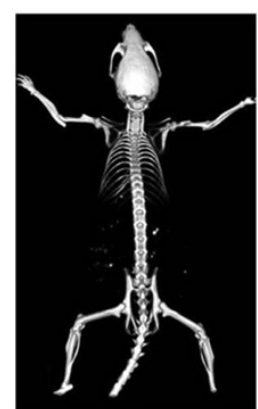

CT

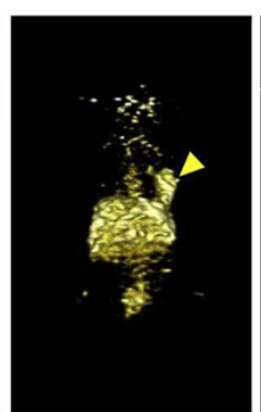

PET

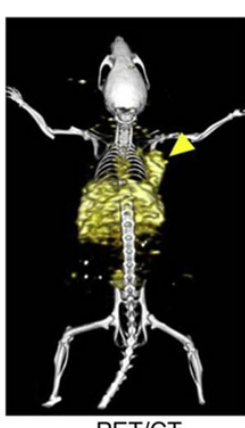

$\mathrm{PET} / \mathrm{CT}$
Figure 11 Representative PET/CT images of ${ }^{66} \mathrm{Ga}$-labeled nanographenes in 4T1 tumor-bearing mice at $3 \mathrm{~h}$ after injection. Tumor site is indicated by arrowheads. Adapted with permission from [126]. 
distinguished by exponential numbers of discrete dendritic branches radiating out from a core [135]. Dendrimers varying in their initiator core, repeating units, terminal functionality, charge, and solubility profile have been synthesized thus far [136,137]; have found diversified applications ranging from the paint industry to desalination plants; and have been tested as diagnostic and drug delivery agents [138]. These nanostructures provide three regions for modification with bioactive agents, namely, the core, branching zone, and branch surface [13]. A few radiolabeled dendrimers have been reported and found to be useful for SPECT and PET imaging studies [139-143]. Almutairi et al. have published the efficacy of biodegradable dendritic structures surfacemodified with a cyclic RGD peptide and with encapsulated ${ }^{76} \mathrm{Br}$ for the targeted delivery and PET imaging of hindlimb ischemia in mice [144]. Zhang et al. have reported the synthesis, biodistribution, and SPECT imaging of three radiolabeled dendrimer conjugates $\left({ }^{99 \mathrm{~m}}\right.$ Tc-dendrimer, ${ }^{99 \mathrm{~m}} \mathrm{Tc}$-dendrimer-folic acid, ${ }^{99 \mathrm{~m}} \mathrm{Tc}$ dendrimer-PEG-folic acid) in KB tumor-bearing mice. The ${ }^{99 \mathrm{~m}}$ Tc-labeled PEGylated dendrimer PAMAM-folic acid conjugates showed higher tumor uptake at $6 \mathrm{~h}$ post-injection $(10.27 \% \quad \mathrm{ID} / \mathrm{g})$ when compared with ${ }^{99 \mathrm{~m}}$ Tc-dendrimer-folic acid $(6.78 \% \mathrm{ID} / \mathrm{g})$ and ${ }^{99 \mathrm{~m}} \mathrm{Tc}$-dendrimer $(4.38 \% \mathrm{ID} / \mathrm{g})$. The MicroSPECT imaging corroborated well with biodistribution data [145].

Nanocapsules are nanoparticules composed of a core, mainly lipophilic, surrounded by a polymeric wall with lipophilic and/or hydrophilic surfactants at the interface [146]. Some studies have been reported using radiolabeled nanocapsules for in vitro and in vivo evaluations [147-150]. Pereira et al. have developed a PEG surfacemodified nanocapsule labeled with technetium-99 m for detecting sites of inflammation. Results showed higher accumulation in inflamed foci than in control tissue, suggesting that such nanostructures can be useful for diagnosing inflammation [151].

Solid lipid nanoparticles are nanoscaled lipid matrices, solid at physiological temperatures and stabilized by surfactants. These nanoparticles are composed of physiological lipids (such as fatty acids and phospholipids) and tend to show high compatibility and biodegradability [152]. Recently, Andreozzi and coworkers have published a novel method to radiolabel solid lipid nanoparticles with ${ }^{64} \mathrm{Cu}$. The mean diameter of the nanoparticles was approximately $150 \mathrm{~nm}$ by dynamic light scattering, and in vivo studies showed a blood half-life of $1.4 \mathrm{~h}$ [153]. Andreozzi's results suggested that solid lipid nanoparticles can be potentially used for diagnostic purposes, suggesting a new field for solid lipid nanoparticles.

Silica nanoparticles have gained extensive attention in biomedical field since they can be utilized in both

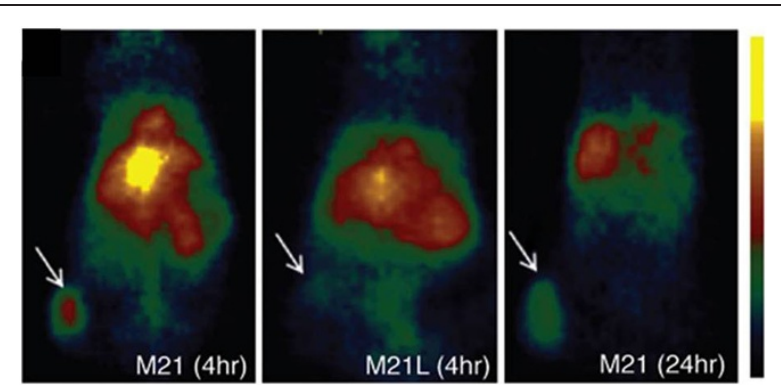

Figure 12 Representative whole-body coronal microPET images. The images were taken $4 \mathrm{~h}$ after injection, demonstrating M21 (left, arrow), M21L (middle, arrow), and enhanced M21 tumor contrast at $24 \mathrm{~h}$ after injection (right, arrow). Adapted with permission from [159].

diagnostic and therapeutic domains [154]. In addition, recent improvements in regulating the geometry, porosity, and surface characteristics of these particles have further enhanced and facilitated their biomedical applications [155-158]. Benezra et al. have reported multimodal silica nanoparticles (c-dots) conjugated with cRGD peptide and labeled with Cy5 dye and ${ }^{124} \mathrm{I}$ for fluorescence and PET imaging, respectively. These 7-nm particles exhibited high-affinity/avidity binding to cells lines, which overexpress $\alpha_{v} \beta_{3}$ integrin receptors (M21, HUVEC). Furthermore, when injected into M21 tumorbearing mice, those particles were able to identify the tumor site, yielding a tumor uptake of $3.6 \% \mathrm{ID} / \mathrm{g}$ (Figure 12). In contrast, after injection into mice with $\mathrm{M} 21 \mathrm{~L}$ tumor (a $\alpha_{\mathrm{v}} \beta_{3}$ integrin nonexpressing cell line), tumor uptake was reduced significantly to $0.7 \% \mathrm{ID} / \mathrm{g}$, indicating specificity to $\alpha_{v} \beta_{3}$ integrin receptors. The US Food and Drug Administration have approved the first human clinical trial of c-dots. The planned clinical trial will involve patients with melanoma, is expected to verify that the dots are both safe and effective in humans, and also will provide promising data for potential future applications [159].

\section{Conclusions}

Nanomedicine has received increasing interest during the past decade since it has become clear that nanoparticles can be used to circumvent some of the difficulties that are associated with the administration of standard drugs. One of the greatest advantages of this field is the ability to generate particles functionalized with a wide variety of targeting ligands and physicochemical properties. This versatility permits the creation of agents that are specifically tailored for each application. In the diagnostic field, radiolabeled nanoparticles have recently emerged as potentially very promising agents for an accurate, reliable, and early diagnosis for several disorders and diseases. These particles provide a means for performing multimodality imaging, which will further 
enhance the rapidly evolving synergy among different techniques (such as, PET/SPECT, MRI, CT, and NIRF). To date, the two major areas where nanoparticles have been applied are cancer and cardiovascular diseases, and some promising results have been reached in both fields. However, in order to attain a nanocarrier with suitable characteristics for biological applications, several factors must be considered. First, nanoparticle characterization should be extensively evaluated before performing animal experiments since in vivo performance is strongly related to shape, charge, surface modification, and size. Second, in vivo stability should be determined since some nanoparticles can be disrupted in the bloodstream. For instance, micelles can decompose back to their unimer forms due to the high plasma dilution. Third, it is extremely important that the radioisotope chelation with diagnostic agents remains stable over the course of imaging. Otherwise, biodistribution and imaging data will not be useful for predicting the fate of nanoparticles, due to the fact that the radioisotope distribution will no longer reflect that of the nanoparticle. In this sense, an appropriate design and use of chelators with high affinity for each isotope should be considered in order to achieve high stability and dependable data. Therefore, strong efforts should be made in order to prepare nanoparticle-based agents which can allow for efficient, specific in vivo delivery of diagnostic agents without systemic toxicity. Although some particles are in clinical trials, such as c-dots, most radiolabeled nanoparticles reported up to now face the challenges and are still in a preclinical stage. We believe that the future of nanomedicine for diagnostic applications lies on the use of multimodal approach by combining different imaging modalities to achieve an accurate diagnosis in cancer, cardiovascular disease, and other disorders. However, although clearly much remains to be done before radiolabeled nanoparticles can be widely adopted for routine clinical applications due to their unusual characteristics, including their extraordinary sensitivity in visualizing the targeted tissues compared to other diagnostic agents, it is likely that such preparations will have a major impact on the diagnostic arena in the near future.

\section{Competing interests}

All authors declare that they have no competing interests.

\section{Authors' contributions}

ALBB reviewed the current literature and wrote the manuscript. BS, VNC, and AT critically reviewed the manuscript. AA provided the concept for the review and critically reviewed and edited the manuscript. All the authors read and approved the final manuscript.

\section{Acknowledgments}

The authors would like to thank Conselho Nacional de Desenvolvimento Científico e Tecnológico (CNPq) - Brazil and Comissão Nacional de Energia Nuclear (CNEN) - Brazil for providing a scholarship to André Luís Branco de Barros.

\section{Author details}

'Pharmacy School, Universidade Federal de Minas Gerais, Belo Horizonte, Minas Gerais 31270-910, Brazil. 'Department of Radiology, Hospital of the University of Pennsylvania, Philadelphia, PA 19104, USA. ${ }^{3}$ Department of Bioengineering, University of Pennsylvania, Philadelphia, PA 19104, USA.

Received: 16 April 2012 Accepted: 5 July 2012

Published: 18 July 2012

\section{References}

1. Moghimi SM, Hunter AC, Murray JC: Nanomedicine: current status and future prospects. FASEB J 2005, 19:311-330.

2. Mailander $V$, Landfester $K$ : Interaction of nanoparitcles with cells. Biomacromolecules 2009, 10:2379-2400.

3. Wagner V, Dullaart A, Bock A, Zweck A: The emerging nanomedicine landscape. Nat Biotechnol 2006, 24:1211-1217.

4. Kim BYS, Rutka JT, Chan WCW: Current concepts: nanomedicine. N Eng J Med 2010, 363:2434-2443.

5. Lewis DR, Kamisoglu K, York AW, Moghe PV: Polymer-based therapeutics: nanoassemblies and nanoparticles for management of atherosclerosis. WIREs Nanomed Nanobiotechnol 2011, 3:400-420.

6. Xia Y, Xiong Y, Lim B, Skrabalak SE: Shape-controlled synthesis of metal nanocrystals: simple chemistry meets complex physics? Angew Chem Int Ed 2009, 48:60-103.

7. Peer D, Karp JM, Hong S, Farokhzad OC, Margalit R, Langer R: Nanocarriers as an emerging platform for cancer therapy. Nat Nanotechnol 2007, 2:751-760.

8. Shenhar R, Norsten TB, Rotello VM: Polymer-mediated nanoparticle assembly: structural control and applications. Adv Mater 2005, 17:657-669.

9. Torchilin VP: Recent advances with liposomes as pharmaceutical carriers. Nat Rev Drug Discov 2005, 4:145-160.

10. Garbazenko O, Barenholz Y, Priev A: Effect of grafted PEG on liposome size and on compressibility and packing of lipid bilayer. Chem Phys Lipids 2005, 135:117-129.

11. Cattel L, Ceruti M, Dosio F: From conventional to stealth liposomes: a new frontier in cancer chemotherapy. Tumori 2003, 89:237-249.

12. Jokerst JV, Lobovkina T, Zare RN, Gambhir SV: Nanoparticle PEGylation for imaging and therapy. Nanomedicine (Lond) 2011, 6:715-728.

13. Gupta AS: Nanomedicine approaches in vascular disease: a review. Nanomedicine: Nanotech Biol Med 2011, 7:763-779.

14. Maeda H, Sawa T, Konno T: Mechanism of tumor-targeted delivery of macromolecular drugs, including the EPR effect in solid tumor and clinical overview of the prototype polymeric drug SMANCS. J Control Release 2001, 74:47-61.

15. Torchilin V: Tumor delivery of macromolecular drugs based on the EPR effect. Adv Drug Del Rev 2011, 63:131-135.

16. Fang J, Nakamure $H$, Maeda $H$ : The EPR effect: unique features of tumor blood vessels for drug delivery, factors involved, and limitations and augmentation of the effect. Adv Drug Del Rev 2011, 63:136-151.

17. Orive G, Ali OA, Anitua E, Pedraz JL, Emerich DF: Biomedical-based technologies for brain anti-cancer therapeutics and imaging. Biochim Biophys Acta 2010, 1806:96-107.

18. Lee H, Li Z, Chen K, Hsu AR, Xu C, Xie J, Sun S, Chen X: PET/MRI dualmodality tumor imaging using arginine-glycine-aspartic (RGD)conjugated radiolabeled iron oxide nanoparticles. J Nucl Med 2008, 49:1371-1379.

19. Kelly KA, Allport JR, Tsourkas A, Shinde-Patil VR, Josephson L, Weissleder R: Detection of vascular adhesion molecule- 1 expression using a novel multimodal nanoparticle. Circ Res 2005, 96:327-336.

20. Nahrendorf M, Jaffer FA, Kelly KA, Sosnovik DE, Aikawa E, Libby P, Weissleder R: Noninvasive vascular cell adhesion molecule- 1 imaging identifies inflammatory activation of cells in atherosclerosis. Circulation 2006, 114:1504-1511.

21. Soares DCF, Oliveria MC, de Barros ALB, Cardoso VN, Ramaldes GA: Liposomes radiolabeled with ${ }^{159} \mathrm{Gd}$ : in vitro antitumoral activity. Biodistribution study and scintigraphic image in Ehrlich tumor bearing mice. Eur J Pharm Sci 2011, 43:290-296.

22. Saul JM, Annapragada AV, Bellamkonda RV: A dual-ligand approach for enhancing targeting selectivity of therapeutic nanocarriers. J Control Release 2006, 114:277-287. 
23. Ying $X$, Wen HE, Lu WL, Du J, Guo J, Tian W, Men Y, Zhang Y, Li RJ, Yang TY, Shang DW, Lou JN, Zhang LR, Zhang Q: Dual-targeting daunorubicin liposomes improve the therapeutic efficacy of brain glioma in animals. J Control Release 2010, 141:183-192.

24. Sinusas AJ, Benjel F, Nahrendorf M, Epstein FH, Wu JC, Villanueva FS, Fayad ZA, Gropler RJ: Multimodality cardiovascular molecular imaging, Part I. Circ Cardiovasc Imaging 2008, 1:244-256.

25. Basu S, Zhuang H, Torigian DA, Rosenbaum J, Chen W, Alavi A: Functional imaging of inflammatory diseases using nuclear medicine techniques. Semin Nucl Med 2009, 39:124-145.

26. Hong H, Zhang $Y$, Sun J, Cai W: Molecular imaging and therapy of cancer with radiolabeled nanoparticles. Nano Today 2009, 4:399-413.

27. Ting G, Chang C, Wang H: Cancer nanotargeted radiopharmaceuticals for tumor imaging and therapy. Anticancer Res 2009, 29:4107-4118.

28. Bangham AD, Standish MM, Watkins JC: Diffusion of univalent ions across the lamellae of swollen phospholipids. J Mol Biol 1965, 13:238-252.

29. De Barros ALB, Mota LG, Soares DCF, Coelho MMA, Oliveira MC, Cardoso VN: Tumor bombesin analog loaded long-circulating and $\mathrm{pH}$-sensitive liposomes as tool for tumor identification. Bioorg Med Chem Lett 2011, 21:7373-7375

30. Damen J, Regts J, Scherphof G: Transfer and exchange of phospholipid between small unilamellar liposomes and rat plasma high density lipoproteins. Dependence on cholesterol content and phospholipid composition. Biochim Biophys Acta 1981, 665:538-545.

31. Sahoo SK, Labhasetwar V: Nanotech approaches to drug delivery and imaging. Drug Discov Today 2003, 8:1112-1120.

32. Senior J, Gregoriadis G: Is half-life of circulating liposomes determined by changes in their permeability? FEBS Lett 1982, 145:109-114.

33. Soenen $\mathrm{SJH}$, Brisson AR, DeCuyper M: Addressing the problem of cationic lipid-mediated toxicity: the magnetoliposome model. Biomaterials 2009, 30:3691-3701

34. Mufamadi MS, Pillay V, Choonara YE, Du Toit LC, Modi G, Naidoo D, Ndesendo MK: A review on composite liposomal technologies for specialized drug delivery. J Drug Deliv 2011, 2011:939851.

35. Torchilin VP: Tat peptide-mediated intracellular delivery of pharmaceutical nanocarriers. Adv Drug Deliv Rev 2008, 60:548-558.

36. Li X, Ding $L, X u Y$, Wang $Y$, Ping Q: Targeted delivery of doxorubicin using stealth liposomes modified with transferring. Int J Pharm 2009, 373:116-123.

37. Song CK, Jung SH, Kim DD, Jeong KS, Shin BC, Seong H: Disaccharidemodified liposomes and their in vitro intracellular uptake. Int J Pharm 2009, 380:161-169.

38. Shmeeda H, Amitay Y, Gorin J, Tzemach D, Mak L, Ogorka J, Kumar S, Zhang JA, Gabizon A: Delivery of zoledronic acid encapsulated in folate-targeted liposome results in potent in vitro cytotoxic activity on tumor cells. $J$ Control Release 2010, 146:76-83.

39. Júnior ADC, Mota LG, Numan EA, Wainstein AJA, Wainstein APDI, Leal AS, Cardoso VN, Oliveira MC: Tissue distribution evaluation of stealth $\mathrm{pH}$ sensitive liposomal cisplatin versus free cisplatin in Ehrlich tumorbearing mice. Life Sci 2007, 80:659-664.

40. Cho EC, Lim HJ, Kim HJ, Son ED, Choi HJ, Park JH, Kim JW, Kim J: Role of $\mathrm{pH}$-sensitive polymer-liposome complex in enhancing cellular uptake of biologically active drugs. Mater Sci Eng 2009, 29:774-778.

41. Oku N, Tokudome Y, Tsukada H, Okada S: Real-time analysis of liposomal trafficking in tumor-bearing mice by use of positron emission tomography. Biochim Biophys Acta 1995, 1238:86-90.

42. Seo JW, Zhang H, Kukis DL, Meares CF, Ferrara KW: A novel method to label preformed liposomes with ${ }^{64} \mathrm{Cu}$ for positron emission tomography (PET) imaging. Bioconjugate Chem 2008, 19:2577-2584.

43. Carmo VA, Ferrari CS, Reis EC, Ramaldes GA, Pereira MA, de Oliveira MC, Cardoso VN: Biodistribution study and identification of inflamation sites using ${ }^{99 \mathrm{~m}} \mathrm{Tc}$-labelled stealth $\mathrm{pH}$-sensitive liposomes. Nucl Med Commun 2008, 29:33-38.

44. Marik J, Tartis MS, Zhang H, Fung JY, Kheirolomoom A, Sutcliffe JL, Ferrara KW: Long-circulating liposomes radiolabeled with [18 F]fluorodipalmitin ([18 F]FDP). Nucl Med Biol 2007, 34:165-171.

45. Li S, Goins B, Zhang L, Bao A: Novel multifunctional theranostic liposome drug delivery system: construction, characterization, and multimodality $\mathrm{MR}$, near-infrared fluorescent, and nuclear imaging. Bioconjugate Chem 2012, 23:1322-1332.
46. Dams ETM, Oyen WJG, Boerman OC, Storm G, Laverman P, Kok PJM, Buijs WCAM, Bakker $\mathrm{H}$, van der Meer JWM, Corstens FHM: ${ }^{99 \mathrm{~m}} \mathrm{Tc}$-PEG liposomes for the scintigraphic detection of infection and inflammation: clinical evaluation. J Nucl Med 2000, 41:622-630.

47. Li D, Patel AR, Klibanov AL, Kramer CM, Ruiz M, Kang B, Mehta JL, Beller GA, Glover DK, Meyer $\mathrm{CH}$ : Molecular imaging of atherosclerosis plaques targeted to oxidized LDL receptor LOX-1 by SPECT/CT and magnetic resonance. Circ Cardiovasc Imaging 2010, 3:464-472.

48. Harrington KJ, Mohammadtaghi S, Uster PS, Glass D, Peters AM, Vile RG, Stewart SW: Effective targeting of solid tumors in patients with locally advanced cancers by radiolabeled pegylated liposomes. Clin Cancer Res 2001, 7:243-254.

49. Chang Y, Chang C, Chang T, Yu C, Chen L, Jan M, Luo T, Lee T, Ting G: Biodistribution, pharmacokinetics and microSPECT/CT imaging of ${ }^{188} \mathrm{Re}-$ BMEDA-liposome in a C26 murine colon carcinoma solid tumor animal model. Anticancer Res 2007, 27:2217-2226.

50. Petersen AL, Binderup T, Rasmussen P, Henriksen JR, Elema DR, Kjaer A Andresen TJ: ${ }^{64} \mathrm{Cu}$ loaded liposomes as positron emission tomography imaging agents. Biomaterials 2011, 32:2334-2341.

51. Pankhurst QA, Connolly J, Jones SK, Dobson J: Applications of magnetic nanoparticles in biomedicine. J Phys D: Appl Phys 2003, 36:R167.

52. Amstad E, Textor M, Reimhult E: Stabilization and functionalization of iron oxide nanoparticles for medical applications. Nanoscale 2011, 3:2819-2843.

53. Choi HS, Liu W, Mirsa P, Tanaka E, Zimmer JP, Ipe BI, Bawendi MG, Frangioni JV: Renal clearance of quantum dots. Nat Biotechnol 2007, 25:1165-1170.

54. Neuberger $T$, Schopf B, Hofmann H, Hofmann M, von Rechenberg B: Superparamagnetic nanoparticles for biomedical applications: possibilities and limitations of a new drug delivery system. J Magn Magn Mater 2005, 293:483-496.

55. Laurent S, Forge D, Port M, Roch A, Robic C, Elst LV, Muller RN: Magnetic iron oxide nanoparticles: synthesis, stabilization, vectorization, physicochemical characterization, and biological applications. Chem Rev 2008, 108:2064-2110.

56. McAteer MA, Akhtar AM, Muhlen C, Choudhury RP: An approach to molecular imaging of atherosclerosis, thrombosis, and vascular inflammation using microparticles of iron oxide. Atherosclerosis 2010, 209:18-27.

57. Elias A, Tsourkas A: Imaging circulating cells and lymphoid tissues with iron oxide nanoparticles. Hematology Am Soc Hematol Educ Program 2009, 2009:720-726

58. Thorek DLJ, Tsourkas A: Size, charge and concentration dependent uptake of iron oxide particles by non-phagocytic cells. Biomaterials 2008 29:3583-3590

59. McCarthy JR, Weissleder R: Multifunctional magnetic nanoparticles for targeted imaging and therapy. Adv Drug Deliv Rev 2008, 11:1241-1251.

60. McCarthy JR, Bhaumik J, Karver MR, Erdem SS, Weissleder R: Target nanoagents for the detection of cancer. Mol Oncol 2010, 4:511-528.

61. Schellenberger EA, Sosnovik D, Weissleder R, Josephson L: Magneto/optical annexin V, a multimodal protein. Bioconjug Chem 2004, 15:1062-1067.

62. Moore A, Medarova Z, Potthast A, Dai G: In vivo targeting of underglycosylated MUC-1 tumor antigen using a multimodal imaging probe. Cancer Res 2004, 64:1821-1827.

63. Quinti L, Weissleder R, Tung CH: A fluorescent nanosensor for apoptotic cells. Nano Lett 2006, 6:488-490.

64. Nahrendorf M, Keliher E, Marinelli B, Waterman P, Feruglio PF, Fexon L, Pivovarov M, Swirski FK, Pittet MJ, Vinegoni C, Weissleder R: Hybrid PET-optical imaging using targeted probes. Proc Natl Acad Sci 2010, 107:7910-7915.

65. Rossin R, Pan D, Qi K, Turner JL, Sun X, Wooley KL, Welch MJ: ${ }^{64}$ Cu-labeled folate-conjugated shell cross-linked nanoparticles for tumor imaging and radiotherapy: synthesis, radiolabeling, and biological evaluation. J NuCl Med 2005, 46:1210-1218.

66. Shokeen M, Fettig NM, Rossin R: Synthesis, in vitro and in vivo evaluation of radiolabeled nanoparticles. Q J Nucl Med Mol Imaging 2008, 52:267-277.

67. Jalilian AR, Panahifar A, Mahmoudi M, Akhlaghi M, Simchi A: Preparation and biological evaluation of [67 Ga]-labeled-superparamagnetic nanoparticles in normal rats. Radiochim Acta 2009, 97:51-56.

68. Devaraj NK, Keliher EJ, Thurber GM, Nahrendorf M, Weissleder R: ${ }^{18} \mathrm{~F}$ labeled nanoparticles for in vivo PET-CT imaging. Bioconjugate Chem 2009, 20:397-401. 
69. Rosales RTM, Tavaré R, Glaria A, Varma G, Protti A, Blower PJ: ${ }^{99 m} \mathrm{Tc}$ bisphosphonate-iron oxide nanoparticle conjugates for dual-modality biomedical imaging. Bioconjugate Chem 2011, 22:455-465.

70. Cizek J, Herholz K, Vollmar S, Schrader R, Klein J, Heiss WD: Fast and robust registration of PET and MR images of human brain. Neurolmage 2004, 22:434-442.

71. Myers R: The application of PET-MR images registration in the brain. $\mathrm{Br}$ Radiol 2002, 75:S31-S35.

72. Mahmoudi M, Serpooshan V, Laurent S: Enginner nanoparticles for biomolecular imaging. Nanoscale 2011, 3:3007-3026.

73. Xie J, Chen K, Huang J, Lee S, Wang J, Gao J, Li X, Chen X: PET/NIRF/MRI triple functional iron oxide nanoparticles. Biomaterials 2010, 31:3016-3022.

74. Nahrendorf $M$, Zhang $H$, Hembrador S, Panizzi P, Sosnovik DE, Alkawa E, Libby P, Swirski FK, Weissleder R: Nanoparticle PET-CT imaging of macrophages in inflammatory atherosclerosis. Circulation 2008, 177:379-387.

75. Narehdorf M, Keliher E, Marinelli B, Leuschner F, Robins CS, Gerszten RE, Pittet MJ, Swirski FK, Weissleder R: Detection of macrophages in aortic aneurysms by nanoparticle PET-CT. Aterioscler Thromb Vasc Biol 2011, 31:750-757

76. Hutter E, Maysinger D: Gold nanoparticles and quantum dots for bioimaging. MicrosC Res Tech 2011, 74:592-604.

77. Thakor AS, Jokerst J, Zavaleta C, Massoud TF, Gambhir SS: Gold nanoparticles: a revival in precious metal administration to patients. Nano Lett 2011, 11:4029-4036.

78. Turkevich J, Steverson PC, Hillier J: A study of the nucleation and growth processes in the synthesis of colloidal gold. Discuss Faraday Soc 1951, 11:55-75.

79. Xie H, Diagaradjane P, Deorukhkar AA, Goins B, Bao A, Phillips WT, Wang Z, Schwartz J, Krishnan S: Integrin $a_{v} \beta_{3}$-targeted gold nanoshells augment tumor vasculature-specific imaging and therapy. Int J Nanomed 2011, 6:259-269.

80. Agarwal A, Shao X, Rajian JR, Zhang H, Chamberland DL, Kotov NA, Wang X: Dual-mode imaging with radiolabeled gold nanorods. J Biomed Opt 2011, 16:051307.

81. Shao X, Agarwal A, Rajaian JR, Kotov NA, Wang X: Synthesis and bioevaluation of ${ }^{125}$ I-labeled gold nanoparticles. Nanotechnology 2011 , 13:135102.

82. Guerrero S, Herance JR, Rojas S, Mena JF, Gispert JD, Acosta GA, Albericio F Kogan MJ: Synthesis and in vivo evaluation of the biodistribution of a 18F-labeled conjugate gold-nanoparticle-peptide with potential biomedical applications. Bioconjugate Chem 2012, 23:399-408.

83. Xie H, Wang ZJ, Bao A, Goins B, Phillips WT: In vivo PET imaging and biodistribution of radiolabeled gold nanoshells in rats with tumor xenografts. Int J Pharm 2010, 395:324-330.

84. Morales-Avila E, Ferro-Flores G, Ocampo-García BE, León-Rodriguez LM, Santos-Cuevas CL, García-Becerra R, Medina LA, Gómez-Oliván L: Multimeric system of ${ }^{99 \mathrm{~m}} \mathrm{Tc}$-labeled gold nanoparticles conjugated to c[RGDfK(C)] for molecular imaging of tumor $a(v) \beta(3)$ expression. Bioconjugate Chem 2011, 22:913-922.

85. Shao X, Zhang H, Rajian JR, Chamberland DL, Sherman OS, Quesada CA Koch $A E$, Kotov NA, Wang $X:{ }^{125}$-labeled gold nanorods for targeted imaging of inflammation. ACS Nano 2011, 5:8967-8973.

86. Janib SM, Moses AS, MacKay JA: Imaging and drug delivery using theranostic nanoparticles. Adv Drug Deliv Rev 2010, 62:1052-1063.

87. Talelli M, Rijcken CJ, van Nostrum CF, Storm G, Hennink WE: Micelles based on HPMA copolymers. Adv Drug Deliv Rev 2010, 62:231-239.

88. Yokoyama M: Clinical applications of polymeric micelle carrier systems in chemotherapy and image diagnosis of solid tumors. J Exp Clin Med 2011, 3:151-158.

89. Nishiyama N, Kataoka K: Current state, achievements, and future prospects of polymeric micelles as nanocarriers for drug and gene delivery. Pharmacol Therapeut 2006, 112:630-648.

90. Koo OM, Rubinstein I, Onyuksel H: Role of nanotechnology in targeted drug delivery and imaging: a concise review. Nanomedicine: Nanotechnol Biol Med 2005, 1:193-212.

91. Trubetskoy VS, Frank-Kamenetsky MD, Whiteman KR, Wolf GL, Torchilin VP: Stable polymeric micelles: lymphangiographic contrast media for gamma scintigraphy and magnetic resonance imaging. Acad Radiol 1996, 3:232-238
92. Patil RR, Yu J, Banerjee SR, Ren Y, Leong D, Jiang X, Pomper M, Tsui B, Kraitchman DL, Mao HQ: Probing in vivo trafficking of polymer/DNA micellar nanoparticles using SPECT/CT imaging. Mol Ther 2011, 19:1626-1635

93. Zhang R, Xiong C, Huang M, Zhou M, Huang Q, Wen X, Liang D: Peptideconjugated polymeric micellar nanoparticles for dual SPECT and optical imaging of EphB4 receptors in prostate cancer xenografts. Biomaterials 2011, 32:5872-5879.

94. Hoang B, Reilly RM, Allen C: Block copolymer micelles target auger electron radiotherapy to the nucleus of HER2-positive breast cancer cells. Biomacromolecules 2012, 13:455-465.

95. Zhang R, Lu W, Wen X, Huang M, Zhou M, Liang D, Li C: Annexin A5conjugated polymeric micelles for dual SPECT and optical detection of apoptosis. J NuCl Med 2011, 52:958-964.

96. Xiao $Y$, Hong H, Javadi A, Engle JW, Xu W, Yang Y, Zhang Y, Bernhart TE, Cai W, Gong S: Multifunctional unimolecular micelles for cancer-targeted drug delivery and positron emission tomography imaging. Biomaterials 2012, 33:3071-3082

97. lijima S: Helical microtubles of graphitic carbon. Nature (London) 1991 354:56-58.

98. Chen RJ, Bangsaruntip S, Drouvalakis KA, Kam NWS, Shim M, Li YM, Kim W, Utz PJ, Dai HJ: Noncovalent functionalization of carbon nanotubes for highly specific electronic biosensors. Proc Nat Acad Sci 2003, 29:4984-4989.

99. Cherukuri P, Bachilo SM, Litovsky SH, Weisman RB: Near-infrared fluorescence microscopy of single-walled carbon nanotubes in phagocytic cells. J Am Chem Soc 2004, 126:15638-15639.

100. Singh R, Pantarotto D, Lacerda L, Pastorin G, Klumpp C, Prato M, Bianco A, Kostarelos K: Tissue biodistribution and blood clearance rates of intravenously administered carbon nanotube radiotracers. Proc Nat Acad Sci 2006, 28:3357-3362.

101. Lacerda L, Soundararajan A, Singh R, Pastorin G, Al-Jamal KT, Turton J, Frederik P, Herrero MA, Li S, Bao A, Emfietzoglou D, Mather S, Phillips WT, Prato M, Bianco A, Goins B, Kostarelos K: Dynamic imaging of functionalized multi-walled carbon nanotube systemic circulation and urinary excretion. Adv Mater 2008, 20:225-230.

102. Deng XY, Yang ST, Nie HY, Wang HF, Liu YF: A generally adoptable radiotracing method for tracking carbon nanotubes in animals. Nanotechnology 2008, 19:075101.

103. Wang HF, Wang J, Deng XY, Sun HF, Shi ZJ, Gu ZN, Liu YF, Zhao YL: Biodistribution of carbon single-wall carbon nanotubes in mice. $J$ Nanosci Nanotechnol 2004, 4:1019-1024.

104. Deng $X$, Jia G, Wang $H$, Sun $H$, Wang $X$, Yang S, Wang T, Liu Y: Translocation and fate of multi-walled carbon nanotubes in vivo. Carbon 2007, 45:1419-1424.

105. McDevitt MR, Chattopadhyay D, Kappel BJ, Jaggi JS, Schiffman SR, Antczak C, Njardarson JT, Brentjens R, Scheinberg DA: Tumor targeting with antibody-functionalized, radiolabeled carbon nanotubes. J Nucl Med 2007, 48:1180-1189.

106. Liu Z, Cai W, He L, Nakayama N, Chen K, Sun X, Chen X, Dai H: In vivo biodistribution and highly efficient tumour targeting of carbon nanotubes in mice. Nat Nanotechnol 2007, 2:47-52.

107. Ruggiero A, Villa CH, Holland JP, Sprinkle SR, May C, Lewis JS, Scheinberg DA, McDevitt MR: Imaging and treating tumor vasculature with targeted radiolabeled carbon nanotubes. Int J Nanomed 2010, 5:783-802

108. Bosi S, Ros TD, Spalluto G, Prato M: Fullerene derivatives: an attractive tool for biological applications. Eur J Med Chem 2003, 5:913-923.

109. Partha R, Conyers JL: Biomedical applications of functionalized fullerrenebased nanomaterials. Int J Nanomed 2009, 4:261-275.

110. Shinohara H: Endohedral metallofullerenes. Rep Prog Phys 2000, 63:843-892

111. Cagle DW, Kennel SJ, Mirzadeh S, Alford JM, Wilson LJ: In vivo studies of fullerene-based materials using endohedral metallofullerene radiotracers. Proc Natl Acad Sci USA 1999, 96:5182-5187.

112. Qingnuan L, Yan X, Xiaodong Z, Ruili L, Qieqie D, Xiaoguang S, Shaoliang C, Wenxin L: Preparation of ${ }^{99 \mathrm{~m}} \mathrm{Tc}_{\mathrm{C}} \mathrm{C}_{60}(\mathrm{OH})_{\mathrm{x}}$ and its biodistribution studies. Nucl Med Biol 2002, 29:707-710.

113. Shultz MD, Duchamp JC, Wilson JD, Shu CY, Ge J, Zhang J, Gibson HW, Fillmore HL, Hirsch J, Dorm HC, Fatouros PP: Encapsulation of a radiolabeled cluster inside a fullerene cage, ${ }^{177} \mathrm{Lu}_{x} \mathrm{Lu}_{(3-x)} \mathrm{N} @ \mathrm{C}_{80}$ : an 
interleukin-13-conjugated radiolabeled metallofullerene platform. J Am Chem Soc 2010, 132:4980-4981.

114. Nickolic N, Vranjes-Duric S, Jankovic D, Dokic D, Mirkovic M, Bibic N, Traikovic V: Preparation and biodistribution of radiolabeled fullerene $C_{60}$ nanocrystals. Nanotechnology 2009, 20:385102.

115. Caruthers SD, Cyrus T, Winter PM, Wickline AS, Lanza GM: Anti-angiogenic perfluorocarbon nanoparticles for diagnosis and treatment of atherosclerosis. WIREs Nanomed Nanobiotechnol 2009, 1:311-323.

116. Lanza GM, Winter PM, Caruthers SD, Hughes MS, Hu G, Schmieder AH, Wickline AS: Theragnostics for tumor and plaque angiogenesis with perfluorocarbon nanoemulsions. Angiogenesis 2010, 13:182-202.

117. Hu G, Lijowski M, Zhang H, Partlow KC, CAruthers SD, Kiefer G, Gulyas G, Athey $P$, Scott MJ, Wickline AS, Lanza GM: Imaging of Vx-2 rabbit tumors with $a_{v} \beta_{3}$-integrin-targeted ${ }^{111}$ In nanoparticles. Int J Cancer 2007, 120:1951-1957.

118. Yang K, Wan J, Zhang S, Tian B, Zhang Y, Liu Z: The influence of surface chemistry and size of nanoscale graphene oxide on photothermal therapy of cancer using ultra-low laser power. Biomaterials 2012, 33:2206-2214

119. Liu Z, Robinson JT, Sun X, Dai H: PEGylated nanographene oxide for delivery of water insoluble cancer drugs. J Am Chem Soc 2008, 130:10876-10877.

120. Sun X, Liu Z, Welsher K, Robinson JT, Goodwin A, Zaric S, Dai H: Nanographene oxide for cellular imaging and drug delivery. Nano Res 2008, 1:203-212.

121. Yang $X$, Zhang X, Liu Z, Ma Y, Huang Y, Chen Y: High efficiency loading and controlled release of doxorubicin hydrochloride on graphene oxide. J Phys Chem C 2008, 112:17554-17558.

122. Lu CH, Yang HH, Zhu CL, Chen $X$, Chen GN: A graphene platform for sensing biomolecules. Angew Chem Int Ed 2009, 48:4785-4787.

123. Loh KP, Bao Q, Eda G, Chhowalla M: Graphene oxide as a chemically tunable platform for optical applications. Nat Chem 2010, 2:1015-1024.

124. Yang K, Wan J, Zhang S, Zhang Y, Lee ST, Liu Z: In vivo pharmacokinetics, long-term biodistribution, and toxicology of PEGylated graphene in mice. ACS Nano 2011, 5:516-522

125. Zhang X, Yin J, Peng C, Hu W, Zhu Z, Li W, Fan C, Huang Q: Distribution and biocompatibility studies of graphene oxide in mice after intravenous administration. Carbon 2011, 49:986-995.

126. Hong H, Zhang Y, Engle JW, Nayak TR, Theuer CP, Nickles RJ, Bernhart TE, Cai $W$ : In vivo targeting and positron emission tomography imaging of tumor vasculature with (66)Ga-labeled nano-graphene. Biomaterials 2012, 33:4147-4156

127. Koo H, Huh MS, Ryu JH, Lee D, Sun I, Choi K, Kim K, Kwon IC: Nanoprobes for biomedical imaging in living systems. Nano Today 2011, 6:204-220.

128. Sakamoto JH, van de Ven AL, Godin B, Blanco E, Serda RE, Grattoni A, Ziemys A, Bouamrami A, Hu T, Ranganathan SI, Rosa E, Martinez IO, Smid CA, Buchanan RM, Lee SY, Srinivasan S, Landry M, Meyn A, Tasciotti E, Liu X, Decussi $P$, Ferrari M: Enabling individualized therapy through nanotechnology. Pharmacol Res 2010, 62:57-89.

129. Woodward JD, Kennel SJ, Mirzadeh S, Daí S, Wall JS, Richey T, Avenell J, Rondinone AJ: In vivo SPECT/CT imaging and biodistribution using radioactive $\mathrm{Cd}^{125 \mathrm{~m}} \mathrm{Te} / \mathrm{ZnS}$ nanoparticles. Nanotechnology 2007, 18:175103.

130. Kennel SJ, Woodward JD, Rondinone AJ, Wall J, Huang Y, Mirzadeh S: The fate of MAb-targeted $\mathrm{Cd}^{125 \mathrm{~m}} \mathrm{Te} / \mathrm{ZnS}$ nanoparticles in vivo. Nucl Med Biol 2008, 35:501-514.

131. Schipper ML, lyer $G$, Koh AL, Chang Z, Ebenstein $Y$, Aharoni A, Keren $S$, Bentolila LA, Li J, Rao J, Chen X, Banin U, Wu AM, Sinclair R, Weiss S, Gambhir SS: Particle size, surface coating, and PEGylation influence the biodistribution of quantum dots in living mice. Small 2009, 5:126-134.

132. Ducongé $F$, Pons $T$, Pestourie $C$, Hérin $L$, Thézé $B$, Gombert $K$, Mahler $B$ Hinnen F, Kuhnast B, Dolle F, Dubertret B, Tavitian B: Fluorine-18-labeled phospholipid quantum dot micelles for in vivo multimodal imaging from whole body to cellular scales. Bioconjugate Chem 2008, 19:1921-1926.

133. Cai W, Chen K, Li Z, Gambhir SS, Chen X: Dual-function probe for PET and near-infrared fluorescene imaging of tumor vasculature. J Nucl Med 2007, 48:1862-1870

134. Chen K, Li Z, Wang H, Cai W, Chen X: Dual-modality optical and positron emission tomography imaging of vascular endothelial growth factor receptor on tumor vasculature using quantum dots. Eur J Nucl Med Mol Imaging 2008, 35:2235-2244.
135. Menjoge AR, Kannan RM, Tomalia DA: Dendrimer-based drug and imaging conjugates: design considerations for nanomedical applications. Drug Discov Today 2010, 15:171-186.

136. Svenson S, Tomalia DA: Dendrimers in biomedical applications reflections on the field. Adv Drug Deliv Rev 2005, 57:2106-2129.

137. Cheng Y, Gao Y, Rao T, Li Y, Xu T: Dendrimer-based prodrugs: design, synthesis, screening and biological evaluation. Comb Chem High Throughput Screen 2007, 10:336-349.

138. Agashe HB, Babbar AK, Jain S, Sharma RK, Misha AK, Asthana A, Grag M, Dutta T, Jain NK: Investigation on biodistribution of technetium-99mlabeled carbohydrate-coated poly(propylene imine) dendrimers. Nanomedicine: Nanotechnol Biol Med 2007, 3:120-127.

139. Kobayashi H, Wu C, Kim MK, Paik CH, Carrasquillo JA, Brechbiel MW: Evaluation of the in vivo biodistribution of Indium-111 and Yttrium-88 labeled dendrimer-1B4M-DTPA and its conjugation with anti-Tac monoclonal antibody. Bioconjugate Chem 1999, 10:103-111.

140. Mamede M, Saga T, Ishimori T, Higashi T, Sato N, Kobayashi H, Brechbiel MW, Konishi J: Hepatocyte targeting of ${ }^{111}$ In-labeled oligo-DNA with avidin or avidin-dendrimer complex. J Control Release 2004, 95:133-141.

141. Kobayashi H, Koyama Y, Barrett T, Hama Y, Regino CA, Shin IS, Jang BS, Le $\mathrm{N}$, Palk $\mathrm{CH}$, Choyke PL, Urano Y: Multimodal nanoprobes for radionuclide and five-color near-infrared optical lymphatic imaging. ACS Nano 2007, $1: 258-264$

142. Hagooley A, Almutairi A, Rossin R, Shokeen M, Ananth A, Anderson C, Abendschein D, Fréchetet Welch M: Evaluation of a RGD-dendrimer labeled with $76 \mathrm{Br}$ in hindlimb ischemia mouse model. J Nucl Med 2008, 49:184.

143. Parrot MC, Benhabbour SR, Saab C, Lemon JA, Parker S, Valliant JF, Adronov A: Synthesis, radiolabeling, and bio-imaging of high-generation polyester dendrimers. J Am Chem Soc 2009, 131:2906-2916.

144. Almutairi A, Rossin R, Shokeen M, Hagooly A, Ananth A, Capoccia B, Guillaudeu S, Abendschein D, Anderson CJ, Welch MJ, Fréchet JMJ: Biodegradable dendritic positron-emitting nanoprobes for the noninvasive imaging of angiogenesis. Proc Natl Acad Sci 2009, 106:685-690.

145. Zhang Y, Sun Y, Xu X, Zhang X, Zhu H, Huang L, Qi Y, Shen YM: Synthesis, biodistribution, and microsingle photon emission computed tomography (SPECT) imaging study of technetium-99m labeled PEGylated dendrimer poly(amidoamine) (PAMAM)-folic acid conjugates. J Med Chem 2010, 53:3262-3272.

146. Legrand P, Barratt G, Mosqueira V, Fessi H, Devissaguet JP: Polymeric nanocapsules as drug delivery systems. A review. STP Pharma Sci 1999, 9:411-418.

147. Assis DN, Mosqueira VCF, Vilela JMC, Andrade MS, Cardoso VN: Release profiles and morphological characterization by atomic force microscopy and photon correlation spectroscopy of ${ }^{99 \mathrm{~m}}$ Technetium-fluconazole nanocapsules. Int J Pharm 2008, 349:152-160.

148. Cahouet A, Denizot B, Hindré F, Passirani C, Heurtault B, Moreau M, Le Jeune JJ, Benoît JP: Biodistribution of dual radiolabeled lipidic nanocapsules in the rat using scintigraphy and $\gamma$ counting. Int J Pharm 2002, 242:367-371.

149. Jestin E, Mougin-Degraef M, Faivre-Chauvet A, Saëc PR, Hindre F, Benoit JP, Chatal JF, Barbet J, GEstin JF: Radiolabeling and targeting of lipidic nanocapsules for application in radioimmunotherapy. Q J Nucl Med Mol Imaging 2007, 51:51-60.

150. Pereira MA, Mosqueira VCF, Vilela JMC, Andrade MS, Ramandes GA, Cardoso VN: PLA-PEG nanocapsules radiolabeled with ${ }^{99 \mathrm{~m}}$ Technetium-HMPAO release properties and physicochemical characterization by atomic force microscopy and photon correlation spectroscopy. Eur J Pharm Sci 2008, 33:42-51.

151. Pereira MA, Mosqueira VCF, Carmo VA, Ferrari CS, Reis ECO, Ramaldes GA, Cardoso VN: Biodistribution study and identification of inflammatory sites using nanocapsules labeled with ${ }^{99 \mathrm{~m}} \mathrm{Tc}$-HMPAO. Nucl Med Commun 2009, 30:749-755.

152. Anton N, Benoit JP, Saulnier P: Design and production of nanoparticles formulated from nano-emulsion templates - a review. J Control Release 2008, 128:185-199.

153. Andreozzi E, Seo JW, Ferrara K, Louie A: Novel method to label solid lipid nanoparticles with ${ }^{64} \mathrm{Cu}$ for positron emission tomography imaging Bioconjugate Chem 2011, 22:808-818. 
154. Liu Y, Mi Y, Zhao J, Feng S: Multifunctional silica nanoparticles for targeted delivery of hydrophobic imaging and therapeutic agents. Int $\rfloor$ Pharm 2011, 421:370-378.

155. Tsai C, Chen C, Hung Y, Chang F, Mou C: Monoclonal antibodyfunctionalized mesoporous silica nanoparticles (MSN) for selective targeting breast cancer cells. J Mater Chem 2009, 19:5737-5743.

156. Zhao Y, Sun X, Zhang G, Trewyn BG, Slowing II, Lin VS: Interaction of mesoporous silica nanoparticles with human red blood cell membranes: size and surface effects. ACS Nano 2011, 5:1366-1375.

157. Tang F, Li L, Chen D: Mesoporous silica nanoparticles: synthesis, biocompatibility and drug delivery. Adv Mater 2012, 24:1504-1534.

158. Hudson SP, Padera RF, Langer R, Kohane DS: The biocompatibility of mesoporous silicates. Biomaterials 2008, 29:4045-4055.

159. Benezra M, Penate-Medina O, Zanzonico PB, Schaer D, Ow H, Burns A, Destanchina E, Longo V, Herz E, Lyer S, Wolchok J, Larson SM, Wiesner U, Bradbury MS: Multimodal silica nanoparticles are effective cancertargeted probes in a model of human melanoma. J Clin Invest 2011, 121:2768-2786.

doi:10.1186/2191-219X-2-39

Cite this article as: de Barros et al:: Emerging role of radiolabeled nanoparticles as an effective diagnostic technique. EJNMMI Research 2012 2:39.

\section{Submit your manuscript to a SpringerOpen ${ }^{\circ}$ journal and benefit from:}

- Convenient online submission

- Rigorous peer review

- Immediate publication on acceptance

- Open access: articles freely available online

- High visibility within the field

- Retaining the copyright to your article 